Federal Reserve Bank of Minneapolis

Research Department Staff Report 371

Revised August 2008

\title{
Time-Varying Risk, Interest Rates, and Exchange Rates in General Equilibrium
}

\author{
Fernando Alvarez* \\ University of Chicago \\ and National Bureau of Economic Research \\ Andrew Atkeson* \\ University of California, \\ Federal Reserve Bank of Minneapolis, \\ and National Bureau of Economic Research \\ Patrick J. Kehoe* \\ Federal Reserve Bank of Minneapolis, \\ University of Minnesota, \\ and National Bureau of Economic Research
}

\begin{abstract}
Under mild assumptions, the data indicate that fluctuations in nominal interest rate differentials across currencies are primarily fluctuations in time-varying risk. This finding is an immediate implication of the fact that exchange rates are roughly random walks. If most fluctuations in interest differentials are thought to be driven by monetary policy, then the data call for a theory which explains how changes in monetary policy change risk. Here we propose such a theory based on a general equilibrium monetary model with an endogenous source of risk variation - a variable degree of asset market segmentation.
\end{abstract}

\footnotetext{
*The authors thank George Marios Angeletos, Martin Boileau, Charles Engel, Michael Devereux, Pierre-Olivier Gourinchas, Juan Pablo Nicolini, Pedro Teles, Chris Telmer, Linda Tesar, Jaume Ventura, and Ivan Werning for helpful comments. The authors also thank the National Science Foundation for financial assistance and Kathy Rolfe and Joan Gieseke for excellent editorial assistance. The views expressed herein are those of the authors and not necessarily those of the Federal Reserve Bank of Minneapolis or the Federal Reserve System.
} 
Overall, the new view of finance amounts to a profound change. We have to get used to the fact that most returns and price variation comes from variation in risk premia. (Cochrane 2001, p. 451)

Cochrane's observation directs our attention to a critical counterfactual part of the standard general equilibrium monetary model: constant risk premia. Variation in risk over time is essential for understanding movements in asset prices; that has been widely documented. Yet the standard model does not generate time-varying risk premia. We develop a simple, general equilibrium monetary model that does. In our model, the asset market is segmented; at any time, only a fraction of the model's agents choose to participate in that market. Risk premia in our model thus vary over time because the degree of asset market segmentation varies over time, endogenously, in response to stochastic shocks.

We apply the model to interest rates and exchange rates because data on those variables provide some of the most compelling evidence that variation in risk premia is a prime mover behind variation in asset prices. In fact, a stylized view of the data on interest rates and exchange rates is that observed variations in interest rate differentials across bonds denominated in different currencies are accounted for almost entirely by variations in risk premia.

To make this view concrete, consider the risk, in nominal terms, faced by a U.S. investor choosing between bonds denominated in either dollars or euros. Clearly, for this investor, the dollar return on the euro bond is risky because next period's exchange rate is not known today. The risk premium compensates the investor who chooses to hold the euro bond for taking on this exchange rate risk. Specifically, in logs, the risk premium $p_{t}$ is equal to the expected log dollar return on a euro bond minus the log dollar return on a dollar bond,

$$
p_{t}=i_{t}^{*}+E_{t} \log e_{t+1}-\log e_{t}-i_{t},
$$

where $i_{t}^{*}$ and $i_{t}$ are the logs of euro and dollar gross interest rates and $e_{t}$ is the exchange rate between the currencies. ${ }^{1}$ The difference in nominal interest rates across currencies can thus be divided into the expected change in the exchange rate between these currencies and a currency risk premium.

In standard equilibrium models of interest rates and exchange rates, since risk premia are constant, interest rate differentials move one-for-one with the expected change in the 
exchange rate. However, nearly the opposite seems to happen in the data: the expected change in the exchange rate is roughly constant and interest differentials move approximately one-for-one with risk premia. More precisely, one view of the data is that exchange rates are roughly random walks, so that the expected depreciation of a currency, $E_{t} \log e_{t+1}-\log e_{t}$, is roughly constant. (See, for example, the discussion in section 9.3.2 of Obstfeld and Rogoff 1996.) Under this view, the interest rate differential, $i_{t}^{*}-i_{t}$, is approximately equal to the risk premium $p_{t}$ plus a constant. The observed variation in the interest rate differential is, thus, almost entirely accounted for by movement in the risk premium.

A more nuanced view of the data is that exchange rates are not exactly random walks; instead, when a currency's interest rate is high, that currency is expected to appreciate. This observation, documented by Fama (1984), Hodrick (1987), and Backus, Foresi, and Telmer (1995), among others, is widely referred to as the forward premium anomaly. The observation seems to contradict intuition, which predicts instead that investors will demand higher interest rates on currencies that are expected to fall, not rise, in value. To explain the data, then, theory requires large fluctuations in risk premia, larger even than those in the interest rate differentials.

Our contribution here is to build a model to exposit a potential mechanism through which changes in monetary policy change risk in a way consistent with the forward premium anomaly. Why should one be interested in such a mechanism? Under mild assumptions, the forward premium anomaly is a demonstration that in the data the changes in interest rate differentials are changes in the risk of investments in different currencies. If most changes in interest rate differentials are thought to be driven by monetary policy changes, then the data call for a theory of how such policy changes change risk. To our knowledge, we are the first to propose such a mechanism. Since the mechanism is new, we keep the analysis simple and transparent. For example, we purposefully abstract from trade in goods in the body. (See Appendix A for an extension of the model that has trade in goods.)

Our model is a two-country, pure exchange, cash-in-advance economy. The key difference between this model and the standard cash-in-advance model is that here agents must pay a fixed cost to transfer money between the goods market and the asset market. We imagine agents as having a brokerage account in the asset market in which they hold a portfolio of 
interest-bearing assets and having to pay a fixed cost to move cash into or out of this account. The cost is similar in spirit to that in the models of Baumol (1952) and Tobin (1956), in that it leads to segmentation of the market in which cash and other money-like assets are traded for bonds and other interest-bearing assets. In our model, the fixed transfer cost differs across agents. In each period, agents with a fixed transfer cost below some cutoff level pay it and thus, at the margin, freely exchange money and bonds. Agents with a fixed transfer cost higher than the cutoff level choose not to pay it, so do not make these exchanges. This is the sense in which our model's asset market is segmented.

The model's mechanism through which asset market segmentation leads to variable risk premia is straightforward. Monetary policy changes change the inflation rate, which changes the net benefit of participating in the asset market. An increase in money growth, for example, increases the fraction of agents that participate in the asset market, reduces the effect of a given money injection on the marginal utility of any participating agent, and thus lowers the risk premium. We show, by way of example, that this type of variable risk premium can be the primary force driving interest rate differentials across currencies and that it can generate the forward premium anomaly.

Essentially, our analysis of the model has two parts. First we develop a monetary model with segmented asset markets that delivers a pricing kernel which we approximate as a log-quadratic function of money growth. The quadratic part of the kernel is the feature through which homoscedastic money growth delivers time-varying risk. In the second part of the analysis, we show that our log-quadratic pricing kernel can generate the forward premium anomaly if the persistence of money growth is in an intermediate range.

In the second part we also present a numerical example which illustrates our model's implications for the behavior of interest rates and exchange rates over time. Our model also has implications for the patterns of long-run averages of interest rate differentials and exchange rate depreciations in a cross section of currencies.

The idea that segmented asset markets can generate large risk premia in certain asset prices is not new. (See, for example, Allen and Gale 1994, Basak and Cuoco 1998, and Alvarez and Jermann 2001.) Existing models, however, focus on generating constant risk premia, which for some applications is relevant. As we have argued, any attempt to account 
for the data on interest rate differentials and exchange rates requires risk premia that are not only large but also highly variable. Unlike other models, ours generates such large and variable premia.

Our model is related to a huge literature on generating large and variable risk premia in general equilibrium models. The work of Mehra and Prescott (1985) and Hansen and Jagannathan (1991) has established that in order to generate large risk premia, the general equilibrium model must produce extremely variable pricing kernels. Also well-known is the fact that because of the data's rather small variations in aggregate consumption, a representative agent model with standard utility functions cannot generate large and variable risk premia. Therefore, attempts to account for foreign exchange risk premia in models of this type fail dramatically. (See Backus, Gregory, and Telmer 1993, Canova and Marrinan 1993, Bansal et al. 1995, Bekaert 1996, Engel 1996, and Obstfeld and Rogoff 2001.) Indeed, the only way such models could generate large and variable risk premia is by generating an implied series for aggregate consumption that both is many times more variable and has a variance that fluctuates much more than that of observed consumption.

Faced with these difficulties, researchers have split the study of risk in general equilibrium models into two branches. One branch investigates new classes of utility functions that make the marginal utility of consumption extremely sensitive to small variations in consumption. The work of Campbell and Cochrane (1999) typifies this branch. Bekaert (1996), Bansal and Shaliastovich (2007), and Lustig and Verdelhan (2007) examine the ability of models along these lines to generate large and variable foreign exchange risk premia. The other research branch investigates limited participation models, in which the consumption of the marginal investor is not equal to aggregate consumption. The work of Alvarez and Jermann (2001) and Lustig and Van Nieuwerburgh (2005) typifies this branch.

Our work here is firmly part of that second branch. In our model, the consumption of the marginal investor is quite variable even though aggregate consumption is essentially constant. For evidence in support of the view that marginal investors have quite variable consumption, see Mankiw and Zeldes (1991), Brav, Constantinides, and Geczy (2002), and Vissing-Jorgensen (2002).

To keep our analysis here simple, we take an extreme view of the limited participation 
idea. In our model, aggregate consumption is (essentially) constant, so it plays no role in pricing risk. Instead, this risk is priced by the marginal investor, whose consumption is quite different from aggregate consumption. In this sense, our model provides a potential resolution to the Backus and Smith (1993) puzzle that fluctuations in real exchange rates are not highly correlated with fluctuations in aggregate consumption.

Backus, Foresi, and Telmer (1995) and Engel (1996) have emphasized that standard monetary models with standard utility functions have no chance of producing the forward premium anomaly because these models generate a constant risk premium whenever the underlying driving processes have constant conditional variances. Backus, Foresi, and Telmer argue that empirically this anomaly is not likely to be generated by primitive processes that have nonconstant conditional variances. (See also Hodrick 1989.) Instead, these researchers argue, what is needed is a model that generates nonconstant risk premia from driving processes that have constant conditional variances. Our model does that.

Our work builds on that of Rotemberg (1985) and Alvarez and Atkeson (1997) and is most closely related to that of our earlier (2002) work. Our work here is also related to that of Grilli and Roubini (1992) and Schlagenhauf and Wrase (1995), who study the effects of money injections on exchange rates in two-country variants of the models of Lucas (1990) and Fuerst (1992). All of these earlier studies focus on how money shocks can lead to variable real exchange rates in models with segmented asset markets. None of them, however, examine the time variation in currency risk premia, which is our central focus. In our 2002 work, in particular, the pricing kernel we developed implies that risk premia are constant over time. Hence, that pricing kernel is clearly irrelevant for addressing the issues we focus on here.

\section{Some Observations on Risk, Interest Rates, and Exchange Rates}

Here we document that fluctuations in interest rate differentials across bonds denominated in different currencies are large, and we develop more fully our argument that these fluctuations are driven mainly by time-varying risk.

\section{A. The Data}

The characteristics of interest rate differentials across bonds denominated in different curren-

cies have been documented in detail by Backus, Foresi, and Telmer (2001). They compute 
statistics on the difference between monthly euro currency interest rates denominated in U.S. dollars and the corresponding interest rates for the other G-7 currencies over the time period July 1974 through November 1994. We display some of these statistics in Table 1. The average of the standard deviations of these interest rate differentials is large: over three percentage points on an annualized basis. (To annualize the monthly standard deviations in Table 1, multiply them by 12.) Moreover, the interest rate differentials are quite persistent: at a monthly level, the average of their first-order autocorrelations is .83.

\section{B. The Argument and the Anomaly}

To see that these large, persistent fluctuations in interest rate differentials are driven mainly by time-varying risk, return to the example in the introduction, where a U.S. investor faced a choice between bonds denominated in either dollars or euros. Again, define the (log) risk premium for a euro-denominated bond as the expected log dollar return on a euro bond minus the log dollar return on a dollar bond. Let $\exp \left(i_{t}\right)$ and $\exp \left(i_{t}^{*}\right)$ be the nominal interest rates on the dollar and euro bonds and $e_{t}$ be the price of euros (foreign currency) in units of dollars (home currency), or the exchange rate between the currencies, in a time period $t$. The dollar return on a euro bond, $\exp \left(i_{t}^{*}\right) e_{t+1} / e_{t}$, is obtained by converting a dollar in period $t$ to $1 / e_{t}$ euros, buying a euro bond paying interest $\exp \left(i_{t}^{*}\right)$, and then converting the resulting euros back to dollars in $t+1$ at the exchange rate $e_{t+1}$. The risk premium $p_{t}$ is then defined as the difference between the expected log dollar return on a euro bond and the log return on a dollar bond:

$$
p_{t}=i_{t}^{*}+E_{t} \log e_{t+1}-\log e_{t}-i_{t}
$$

Clearly, the dollar return on the euro bond is risky because the future exchange rate $e_{t+1}$ is not known in $t$. The risk premium compensates the holder of the euro bond for accepting this exchange rate risk.

To see our argument in its simplest form, suppose that the exchange rate follows a random walk, so that the expected depreciation of a currency, $E_{t} \log e_{t+1}-\log e_{t}$, is constant. Since (1) implies that

$$
i_{t}-i_{t}^{*}=-p_{t}+E_{t} \log e_{t+1}-\log e_{t}
$$


the interest rate differential is just the risk premium plus a constant. Hence, all of the movements in the interest rate differential are matched by corresponding movements in the risk premium so that

$$
\operatorname{var}\left(p_{t}\right)=\operatorname{var}\left(i_{t}-i_{t}^{*}\right)
$$

In the data, however, exchange rates are only approximately random walks. In fact, one of the most puzzling features of the exchange rate data is the tendency for high interest rate currencies to appreciate, in that

$$
\operatorname{cov}\left(i_{t}-i_{t}^{*}, \log e_{t+1}-\log e_{t}\right) \leq 0
$$

which is equivalent to

$$
\operatorname{cov}\left(i_{t}-i_{t}^{*}, E_{t} \log e_{t+1}-\log e_{t}\right) \leq 0
$$

The inequality (3) implies that exchange rates are not random walks, because expected depreciation rates are correlated with interest rate differentials.

This tendency for high interest rate currencies to appreciate has been widely documented for the currencies of the major industrialized countries over the period of floating exchange rates. (For a recent discussion, see, for example, Backus, Foresi, and Telmer 2001.) The inequality (3) is commonly referred to as the forward premium anomaly. ${ }^{2}$ In the literature, this anomaly is documented by a regression of the change in the exchange rates on the interest rate differential of the form

$$
\log e_{t+1}-\log e_{t}=a+b\left(i_{t}-i_{t}^{*}\right)+u_{t+1}
$$

Such regressions typically yield estimates of $b$ that are zero or negative. We refer to $b$ as the slope coefficient in the Fama regression.

The estimated size of $b$ is particularly puzzling because $b \leq 0$ implies that fluctuations in risk premia that are needed to account for fluctuations in interest differentials are even larger than those needed if exchange rates followed random walks: ${ }^{3}$

$$
\operatorname{var}\left(p_{t}\right) \geq \operatorname{var}\left(i_{t}-i_{t}^{*}\right) .
$$


It is easy to see that $b \leq 0$ implies that

$$
\operatorname{cov}\left(E_{t} \log e_{t+1}-\log e_{t}, p_{t}\right)>0
$$

and that

$$
\operatorname{var}\left(p_{t}\right) \geq \operatorname{var}\left(E_{t} \log e_{t+1}-\log e_{t}\right)
$$

In other words, the finding that the slope coefficient in the Fama regression is negative implies that exchange rates are expected to appreciate when the risk premium falls and that the movement in the risk premium is larger than the expected appreciation of the exchange rate.

\section{A Model with Time-Varying Risk}

We now describe a model - first generally and then in detail - that can generate the observations just discussed. It is a general equilibrium monetary model with segmented markets that generates time-varying risk premia. After developing this model, we characterize its equilibrium values of consumption and real balances and show how money growth in the model is linked to the marginal utility of its asset market participants.

\section{A. An Outline}

We start by sketching out the basic structure of our model.

Consider a two-country, cash-in-advance economy with an infinite number of periods $t=0,1,2, \ldots$ Call one country the home country and the other the foreign country. Each country has a government and a continuum of households of measure one. Households in the home country use the home currency, dollars, to purchase a home good. Households in the foreign country use the foreign currency, euros, to purchase a foreign good.

Trade in this economy in periods $t \geq 1$ occurs in three separate locations: an asset market available to both countries and one goods market in each country. In the asset market, households trade the two currencies and dollar and euro bonds, which promise delivery of the relevant currency in the asset market in the next period, and the two countries' governments introduce their currencies via open market operations. In each goods market, households use the local currency to buy the local good subject to a cash-in-advance constraint and sell their 
endowment of the local good for local currency. In period 0 there is an initial round of trade in bonds in the asset market with no trade in goods markets.

Each household must pay a real fixed cost $\gamma$ for each transfer of cash between the asset market and a goods market. This fixed cost is constant over time for any specific household, but it varies across households in both countries according to a distribution $F(\gamma)$ with density $f(\gamma){ }^{4}$ Households are indexed by their fixed cost $\gamma$. The fixed costs for households in each country are in units of the local good. We assume $F(0)>0$, so that a positive mass of households has a zero fixed cost.

The only source of uncertainty in this economy is shocks to money growth in the two countries. The timing within each period $t \geq 1$ for a household in the home country is illustrated in Figure 1. We emphasize the physical separation of the markets by separating them in the figure. Households in the home country enter the period with the cash $P_{-1} y$ they obtained from selling their home good endowments in $t-1$, where $P_{-1}$ is the price level and $y$ is their endowment of their home good. Each government conducts an open market operation in the asset market, which determines the realizations of money growth rates $\mu$ and $\mu^{*}$ in the two countries and the current price levels in the two countries $P$ and $P^{*}$.

The household then splits into a worker and a shopper. Each period the worker sells the household endowment $y$ for cash $P y$ and rejoins the shopper at the end of the period. The shopper takes the household's cash $P_{-1} y$ with real value $n=P_{-1} y / P$ and shops for goods. The shopper can choose to pay the fixed cost $\gamma$ to transfer an amount of cash $P x$ with real value $x$ to or from the asset market. This fixed cost is paid in cash obtained in the asset market. If the shopper pays the fixed cost, then the cash-in-advance constraint is that consumption $c=n+x$; otherwise, this constraint is $c=n$.

The household also enters the period with bonds that are claims to cash in the asset market with payoffs contingent on the rates of money growth $\mu$ and $\mu^{*}$ in the current period. This cash can be either reinvested in the asset market or, if the fixed cost is paid, transferred to the goods market. With $B$ denoting the current payoff of the state-contingent bonds purchased in the past, $q$ the price of bonds, and $\int q B^{\prime}$ the household's purchases of new bonds, the asset market constraint is $B=\int q B^{\prime}+P(x+\gamma)$ if the fixed cost is paid and $B=\int q B^{\prime}$ otherwise. At the beginning of period $t+1$, the household starts with cash $P y$ in 
the goods market and a portfolio of contingent bonds $B^{\prime}$ in the asset market.

In equilibrium, households with a sufficiently low fixed cost pay it and transfer cash between the goods and asset markets while others do not. We refer to households that pay the fixed cost as active and those that do not as inactive. Inactive households simply consume their current real balances.

Throughout, we assume that the shoppers are not allowed to store cash from one period to the next. This assumption implies that the cash-in-advance constraint holds with equality and greatly simplifies the analysis. For some models in which agents are allowed to store cash and end up doing so in equilibrium, see the work of Alvarez, Atkeson, and Edmond (2003) and Khan and Thomas (2007).

We also assume throughout that in the asset market, households hold their assets in interest-bearing bonds rather than cash. Note that as long as nominal interest rates are positive, bonds dominate cash held in the asset market.

\section{B. The Details}

Now we flesh out this outline of the economy.

Let $M_{t}$ denote the stock of dollars in period $t$, and let $\mu_{t}=M_{t} / M_{t-1}$ denote the growth rate of this stock. Similarly, let $\mu_{t}^{*}$ be the growth rate of the stock of euros $M_{t}^{*}$. Let $s_{t}=\left(\mu_{t}, \mu_{t}^{*}\right)$ denote the aggregate event in period $t$. Then let $s^{t}=\left(s_{1}, \ldots, s_{t}\right)$ denote the state, consisting of the history of aggregate events through period $t$, and let $g\left(s^{t}\right)$ denote the density of the probability distribution over such histories.

In period 0 there is an initial round of trade in bonds in the asset market with no trade in goods markets. In the asset market in period 0, home households of type $\gamma$ have $M_{0}$ units of home money (dollars), $\bar{B}_{h}(\gamma)$ units of the home government debt (bonds), and $\bar{B}_{h}^{*}$ units of the foreign government debt, which are claims on $\bar{B}_{h}(\gamma)$ dollars and $\bar{B}_{h}^{*}$ euros in the asset market in that period. Likewise, in the asset market in period 0 foreign households start with $M_{0}^{*}$ euro holdings in the foreign goods market, $\bar{B}_{f}$ units of the home government debt, and $\bar{B}_{f}^{*}(\gamma)$ units of the foreign government debt in the asset market.

The home government issues one-period dollar bonds contingent on the aggregate state $s^{t}$. In period $t$, given state $s^{t}$, the home government pays off outstanding bonds $B\left(s^{t}\right)$ 
in dollars and issues claims to dollars in the next asset market of the form $B\left(s^{t}, s_{t+1}\right)$ at prices $q\left(s^{t}, s_{t+1}\right)$. Let $\bar{B}$ denote the stock of outstanding dollar bonds at the beginning of period 0 . The home government budget constraint at $s^{t}$ with $t \geq 1$ is

$$
B\left(s^{t}\right)=M\left(s^{t}\right)-M\left(s^{t-1}\right)+\int_{s_{t+1}} q\left(s^{t}, s_{t+1}\right) B\left(s^{t}, s_{t+1}\right) d s_{t+1}
$$

with $M\left(s^{0}\right)=\bar{M}$ given, and in $t=0$, the constraint is $\bar{B}=\int_{s_{1}} q\left(s^{1}\right) B\left(s^{1}\right) d s_{1}$. Likewise, the foreign government issues euro bonds denoted $B^{*}\left(s^{t}\right)$ with bond prices denoted $q^{*}\left(s^{t}, s_{t+1}\right)$. The budget constraints for the foreign government are then analogous to the home government's constraints above.

In the asset market in each period and state, home households trade a complete set of one-period dollar bonds and euro bonds that have payoffs next period contingent on the aggregate event $s_{t+1}$. Arbitrage between these bonds then implies that

$$
q\left(s^{t}, s_{t+1}\right)=q^{*}\left(s^{t}, s_{t+1}\right) e\left(s^{t}\right) / e\left(s^{t+1}\right),
$$

where $e\left(s^{t}\right)$ is the exchange rate for one euro in terms of dollars in state $s^{t}$. This arbitrage relationship implies that the home and foreign bonds are each separately a complete set of state-contingent assets. Thus, without loss of generality, we can assume that home households hold only home bonds and foreign households hold only foreign bonds.

Consider now the problem of households of type $\gamma$ in the home country. Let $P\left(s^{t}\right)$ denote the price level in dollars in the home goods market in period $t$. In each period $t \geq 1$, in the goods market, these households start the period with dollar real balances $n\left(s^{t}, \gamma\right)$. They then choose transfers of real balances between the goods market and the asset market $x\left(s^{t}, \gamma\right)$, an indicator variable $z\left(s^{t}, \gamma\right)$ equal to zero if these transfers are zero and one if they are more than zero, and consumption of the home good $c\left(s^{t}, \gamma\right)$ subject to the cash-in-advance constraint and the transition law,

$$
\begin{aligned}
& c\left(s^{t}, \gamma\right)=n\left(s^{t}, \gamma\right)+x\left(s^{t}, \gamma\right) z\left(s^{t}, \gamma\right) \\
& n\left(s^{t+1}, \gamma\right)=\frac{P\left(s^{t}\right) y}{P\left(s^{t+1}\right)}
\end{aligned}
$$


where in (10) in $t=1$, the term $n\left(s^{1}, \gamma\right)$ is given by $M_{0} / p\left(s^{1}\right)$. In the asset market in $t \geq 1$, home households begin with cash payments $B\left(s^{t}, \gamma\right)$ on their bonds. They purchase new bonds and make cash transfers to the goods market subject to the sequence of budget constraints

$$
B\left(s^{t}, \gamma\right)=\int_{s_{t+1}} q\left(s^{t}, s_{t+1}\right) B\left(s^{t}, s_{t+1}, \gamma\right) d s_{t+1}+P\left(s^{t}\right)\left[x\left(s^{t}, \gamma\right)+\gamma\right] z\left(s^{t}, \gamma\right)
$$

Assume that both consumption $c\left(s^{t}, \gamma\right)$ and real bond holdings $B\left(s^{t}, \gamma\right) / P\left(s^{t}\right)$ are uniformly bounded by some large constants.

In period 0 , the asset market constraint for home households is given by

$$
\bar{B}_{h}(\gamma)+e_{0} \bar{B}_{h}^{*}=\int_{s_{1}} q\left(s_{1}\right) B\left(s_{1}, \gamma\right) d s_{1}
$$

In this initial period, home and foreign households trade bonds denominated in the two currencies and insure themselves against the initial money growth shock $s_{1}$.

The problem of the home household of type $\gamma$ is to maximize utility

$$
\sum_{t=1}^{\infty} \beta^{t} \int U\left(c\left(s^{t}, \gamma\right)\right) g\left(s^{t}\right) d s^{t}
$$

subject to the constraints (10)-(12). Households in the foreign country solve the analogous problem, with $P^{*}\left(s^{t}\right)$ denoting the price level in euros in the foreign country goods market. We require that $\int \bar{B}_{h}(\gamma) f(\gamma) d \gamma+\bar{B}_{f}=\bar{B}$ and $\bar{B}_{h}^{*}+\int \bar{B}_{f}^{*}(\gamma) f(\gamma) d \gamma=\bar{B}^{*}$.

Since each transfer of cash between the asset market and the home goods market consumes $\gamma$ units of the home good, the total goods cost of carrying out all transfers between home households and the asset market in $t$ is $\gamma \int z\left(s^{t}, \gamma\right) f(\gamma) d \gamma$, and likewise for the foreign households. The resource constraint in the home country is given by

$$
\int\left[c\left(s^{t}, \gamma\right)+\gamma z\left(s^{t}, \gamma\right)\right] f(\gamma) d \gamma=y
$$

for all $t, s^{t}$, with the analogous constraint in the foreign country. The fixed costs are paid for with cash obtained in the asset market. Thus, the home country money market-clearing condition in $t \geq 1$ is given by

$$
\int\left(n\left(s^{t}, \gamma\right)+\left[x\left(s^{t}, \gamma\right)+\gamma\right] z\left(s^{t}, \gamma\right)\right) f(\gamma) d \gamma=M\left(s^{t}\right) / P\left(s^{t}\right)
$$

for all $s^{t}$. The money market-clearing condition for the foreign country is analogous. We let $c$ denote the sequences of functions $c\left(s^{t}, \gamma\right)$ and use similar notation for the other variables. 
An equilibrium in this economy is a collection of bond and goods prices $\left(q, q^{*}\right)$ and $(P$, $\left.P^{*}\right)$, together with bond holdings $\left(B, B^{*}\right)$ and allocations for home and foreign households $(c, x, z, n)$ and $\left(c^{*}, x^{*}, z^{*}, n^{*}\right)$, such that for each transfer cost $\gamma$, the bond holdings and the allocations solve the households' utility maximization problems, the governments' budget constraints hold, and the resource constraints and the money market-clearing conditions are satisfied.

\section{Characterizing Equilibrium}

Now, in our model economy, we solve for the equilibrium consumption and real balances of both active households (those that pay the fixed cost and transfer cash between asset and goods markets) and inactive households (those that do not). We then characterize the link between the consumption of active households and asset prices. We focus on households in the home country; the analysis of households in the foreign country is similar.

\section{Consumption and Real Balances}

We start with a household's decision whether or not to pay the fixed cost in order to transfer cash between the asset and goods markets. Since households are not allowed to store cash in the goods market, the cash-in-advance constraint always binds, and any household's decision to pay the fixed cost in period $t$ is static. This is because this decision affects only the household's current consumption and bond holdings and not the real balances it holds later in the goods market.

Notice that the constraints (10), (14), and (15) imply that the price level is

$$
P\left(s^{t}\right)=M\left(s^{t}\right) / y
$$

The inflation rate is $\pi_{t}=\mu_{t}$, and real money holdings are $n\left(s^{t}, \gamma\right)=y / \mu_{t}$. Hence, the consumption of inactive households is $c\left(s^{t}, \gamma\right)=y / \mu_{t}$. Let $c_{A}\left(s^{t}, \gamma\right)$ denote the consumption of an active household for a given $s^{t}$ and $\gamma$.

In this economy, inflation is distorting because it reduces the consumption of any household that chooses to be inactive. This effect induces some households to use real resources to pay the fixed cost, thereby reducing the total amount of resources available for consumption. This is the only distortion from inflation in the model. Because of this feature 
and our assumption that a complete set of nominal claims are traded in the asset market, the competitive equilibrium allocations and asset prices can be found from the solution to the following planning problem for the home country, together with that to the analogous problem for the foreign country. ${ }^{5}$ Choose $z\left(s^{t}, \gamma\right) \in[0,1], c\left(s^{t}, \gamma\right) \geq 0$, and $c\left(s^{t}\right) \geq 0$ to solve

$$
\max \sum_{t=1}^{\infty} \beta^{t} \int_{s^{t}} \int_{\gamma} U\left(c\left(s^{t}, \gamma\right)\right) f(\gamma) g\left(s^{t}\right) d \gamma d s^{t}
$$

subject to the resource constraint (14) and this additional constraint:

$$
c\left(s^{t}, \gamma\right)=z\left(s^{t}, \gamma\right) c_{A}\left(s^{t}, \gamma\right)+\left[1-z\left(s^{t}, \gamma\right)\right] y / \mu_{t}
$$

The constraint (17) captures the restriction that the consumption of households that do not pay the fixed cost is pinned down by their real money balances $y / \mu_{t}$. Here the planning weight for households of type $\gamma$ is simply the fraction of households of this type.

This planning problem can be decentralized with the appropriate settings of the initial endowments of home and foreign government debt $\bar{B}(\gamma)$ and $\bar{B}^{*}(\gamma)$. Asset prices are obtained from the multipliers on the resource constraints above. For simplicity, we have chosen to focus on the economy in which initial bond holdings are allocated so that all households have equal Lagrange multipliers on their period 0 budget constraints. The equilibrium allocations of this economy correspond to those found as the solution to the planning problem with equal Pareto weights given above. (Economies with different distributions of bond holdings have equilibrium allocations that correspond to planning problems that have Pareto weights that depend on $\gamma$. )

Notice that the planning problem reduces to a sequence of static problems. We analyze the consumption pattern first for a fixed choice $z$ to pay the fixed cost and then for the optimal choice of $z$.

The first-order condition for an active household's consumption $c_{A}$ reduces to

$$
\beta^{t} U^{\prime}\left(c_{A}\left(s^{t}, \gamma\right)\right) g\left(s^{t}\right)=\lambda\left(s^{t}\right)
$$

where $\lambda\left(s^{t}\right)$ is the multiplier on the resource constraint. This first-order condition clearly implies that all households that pay the fixed cost choose the same consumption level, which means that $c_{A}\left(s^{t}, \gamma\right)$ is independent of $\gamma$. Since this problem is static, this consumption level 
depends on only the current money growth shock $\mu_{t}$. Hence, we denote this consumption as $c_{A}\left(\mu_{t}\right)$.

Now, since the solution to the planning problem depends on only current $\mu_{t}$ and $\gamma$, we drop its dependence on $t$. It should be clear that the optimal choice of $z$ has a cutoff rule form: for each shock $\mu$, there is some fixed cost level $\bar{\gamma}(\mu)$ at which the households with $\gamma \leq$ $\bar{\gamma}(\mu)$ pay this fixed cost and consume $c_{A}(\mu)$, and all other households (the inactive ones) do not pay and consume instead $y / \mu$. For each $\mu$, the planning problem thus reduces to choosing two numbers, $c_{A}(\mu)$ and $\bar{\gamma}(\mu)$, to solve

$$
\max U\left(c_{A}(\mu)\right) F(\bar{\gamma}(\mu))+U(y / \mu)[1-F(\bar{\gamma}(\mu))]
$$

subject to

$$
c_{A}(\mu) F(\bar{\gamma}(\mu))+\int_{0}^{\bar{\gamma}(\mu)} \gamma f(\gamma) d \gamma+(y / \mu)[1-F(\bar{\gamma}(\mu))]=y
$$

The first-order conditions then can be summarized by (19) and

$$
U\left(c_{A}(\mu)\right)-U(y / \mu)-U^{\prime}\left(c_{A}(\mu)\right)\left[c_{A}(\mu)+\bar{\gamma}(\mu)-(y / \mu)\right]=0 .
$$

In Appendix B, we show that the solution to these two equations, (19) and (20)-namely, $c_{A}(\mu)$ and $\bar{\gamma}(\mu)$-is unique. We then can describe the equilibrium consumption and real balances of active and inactive households in the following proposition:

Proposition 1. The equilibrium consumption of households is given by

$$
c\left(s^{t}, \gamma\right)= \begin{cases}c_{A}\left(\mu_{t}\right) & \text { if } \gamma \leq \bar{\gamma}\left(\mu_{t}\right) \\ y / \mu_{t} & \text { otherwise }\end{cases}
$$

where the functions $c_{A}(\mu)$ and $\bar{\gamma}(\mu)$ are the solutions to (19) and (20).

\section{Active Household Consumption and Asset Prices}

Now we characterize the link between the consumption of active households and asset prices.

In the decentralized economy corresponding to the planning problem, asset prices are given by the multipliers on the resource constraints for the planning problem. Here, from (18), these multipliers are equal to the marginal utility of active households. 
Hence, the pricing kernel for dollar assets is

$$
m\left(s^{t}, s_{t+1}\right)=\beta \frac{U^{\prime}\left(c_{A}\left(\mu_{t+1}\right)\right)}{U^{\prime}\left(c_{A}\left(\mu_{t}\right)\right)} \frac{1}{\mu_{t+1}},
$$

while the pricing kernel for euro assets is

$$
m^{*}\left(s^{t}, s_{t+1}\right)=\beta \frac{U^{\prime}\left(c_{A}^{*}\left(\mu_{t+1}^{*}\right)\right)}{U^{\prime}\left(c_{A}^{*}\left(\mu_{t}^{*}\right)\right)} \frac{1}{\mu_{t+1}^{*}} .
$$

These kernels are the state-contingent prices for dollars and euros normalized by the probabilities of the state.

These pricing kernels can price any dollar or euro asset. In particular, the pricing kernels immediately imply that any asset purchased in period $t$ with a dollar return of $R_{t+1}$ between periods $t$ and $t+1$ satisfies the Euler equation

$$
1=E_{t} m_{t+1} R_{t+1}
$$

where, for simplicity here and in much of what follows, we drop the $s^{t}$ notation. Likewise, every possible euro asset with rate of return $R_{t+1}^{*}$ from $t$ to $t+1$ satisfies the Euler equation

$$
1=E_{t} m_{t+1}^{*} R_{t+1}^{*} .
$$

Note that $\exp \left(i_{t}\right)$ is the dollar return on a dollar-denominated bond with interest rate $i_{t}$, and $\exp \left(i_{t}^{*}\right)$ is the expected euro return on a euro-denominated bond with interest rate $i_{t}^{*}$; these Euler equations thus imply that

$$
i_{t}=-\log E_{t} m_{t+1} \text { and } i_{t}^{*}=-\log E_{t} m_{t+1}^{*} .
$$

The pricing kernels for dollars and euros have a natural relation: $m_{t+1}^{*}=m_{t+1} e_{t+1} / e_{t}$. This can be seen as follows. Every euro asset with euro rate of return $R_{t+1}^{*}$ has a corresponding dollar asset with rate of return $R_{t+1}=R_{t+1}^{*} e_{t+1} / e_{t}$ formed when an investor converts dollars into euros in $t$, buys the euro asset, and converts the return back into dollars in $t+1$. Equilibrium requires that

$$
1=E_{t} m_{t+1} R_{t+1}=E_{t}\left\{\left[m_{t+1}\left(\frac{e_{t+1}}{e_{t}}\right)\right] R_{t+1}^{*}\right\} .
$$

Since (26) holds for every euro return, $m_{t+1} e_{t+1} / e_{t}$ is an equilibrium pricing kernel for euro assets. Complete asset markets have only one euro pricing kernel, so

$$
\log e_{t+1}-\log e_{t}=\log m_{t+1}^{*}-\log m_{t+1} .
$$


Substituting (25) and (27) into our original expression for the risk premium (1) gives that

$$
p_{t}=\left(E_{t} \log m_{t+1}^{*}-E_{t} \log m_{t+1}\right)-\left(\log E_{t} m_{t+1}^{*}-\log E_{t} m_{t+1}\right) .
$$

Hence, a currency's risk premium depends on the difference between the expected value of the log and the log of the expectation of the pricing kernel. Jensen's inequality implies that fluctuations in the risk premium are driven by fluctuations in the conditional variability of the pricing kernel.

Finally, note that given the initial exchange rate $e_{0}$ and (27) together with the kernels gives the entire path of the nominal exchange rate $e_{t}$. It is easy to show that the initial nominal exchange rate is given by

$$
e_{0}=\left(\bar{B}-\bar{B}_{h}\right) / \bar{B}_{h}^{*}
$$

where $\bar{B}_{h}=\int \bar{B}_{h}(\gamma) d F(\gamma)$. Clearly, this exchange rate exists and is positive as long as either $\bar{B}_{h}<\bar{B}$ and $\bar{B}_{h}^{*}>0$ or $\bar{B}_{h}>\bar{B}$ and $\bar{B}_{h}^{*}<0$.

\section{Linking Money Growth and Active Households' Marginal Utility}

In our model, the active households price assets in the sense that the pricing kernels (21) and (22) are determined by those households' marginal utilities. Thus, in order to characterize the link between money growth and either interest rates or exchange rates, we need to determine how these marginal utilities respond to changes in money growth, namely, how $U^{\prime}\left(c_{A}\left(\mu_{t}\right)\right)$ varies with $\mu_{t}$.

\section{The Theory}

In the simplest monetary models (such as in Lucas 1982), all the agents are active every period, and changes in money growth have no impact on marginal utilities. Our model introduces two key innovations to those simple models. One is that here, because of the segmentation of asset markets, changes in money growth do have an impact on the consumption and, hence, the marginal utility of active households. Our model's other innovation is that the size of this impact changes systematically with the size of money growth. As we show, the change in the size of this impact can be large because the degree of market segmentation is endogenous. With these two innovations, our model can deliver large and variable currency risk premia even though the fundamental shocks have constant variance. 
Mechanically, our model generates variable risk premia that fall as money growth rises when $\log c_{A}(\mu)$ is increasing and concave in $\log \mu$. To see the link between risk premia and $\log c_{A}(\mu)$, define $\phi(\mu)$ to be the elasticity of the marginal utility of active households to a change in money growth. With constant relative risk aversion preferences of the form $U(c)=c^{1-\sigma} /(1-\sigma)$, where $\sigma$ is the degree of relative risk aversion, this elasticity is given by

$$
\phi(\mu) \equiv-\frac{d \log U^{\prime}\left(c_{A}(\mu)\right)}{d \log \mu}=\sigma \frac{d \log c_{A}(\mu)}{d \log \mu} .
$$

Note from (30) that when $\log c_{A}(\mu)$ is increasing in $\log \mu, \phi(\mu)>0$. The larger is $\phi(\mu)$, the more sensitive is the marginal utility of active households to money growth. Also note that when $\log c_{A}(\mu)$ is concave in $\log \mu, \phi(\mu)$ decreases in $\mu$; this means the marginal utility of active households is more sensitive to money growth changes at low levels of money growth than at high. In this sense, the concavity of $\log c_{A}(\mu)$ implies that the variability of the pricing kernel decreases as money growth increases.

We now characterize features of our model's equilibrium in two propositions. The proofs of both are in Appendix B.

Proposition 2. As $\mu$ increases, more households become active. In particular, $\bar{\gamma}^{\prime}(\mu)>0$ for $\mu>1$, and $\bar{\gamma}^{\prime}(1)=0$.

Proposition 3. The log of the consumption of active households $c_{A}(\mu)$ is strictly increasing and strictly concave in $\log \mu$ around $\mu=1$. In particular, $\phi(1)>0$ and $\phi^{\prime}(1)<0$.

In Proposition 2, we have shown that more households choose to become active as money growth and inflation increase. This result is intuitive because as inflation increases, so does the cost of not participating in the asset market, since the consumption of inactive households, $y / \mu$, falls as money growth $\mu$ increases.

In Proposition 3, we have shown that locally, for low values of money growth at least, the consumption of active households is increasing and concave in money growth.

\section{A Quadratic Approximation}

To capture the nonlinearity of $c_{A}(\mu)$ in a tractable way for computing the asset prices implied by our model, we take a second-order approximation to the marginal utility of active 
households of the form

$$
\log U^{\prime}\left(c_{A}\left(\mu_{t}\right)\right)=\log U^{\prime}\left(c_{A}(\bar{\mu})\right)-\phi \hat{\mu}_{t}+\frac{1}{2} \eta \hat{\mu}_{t}^{2},
$$

where $\hat{\mu}_{t}=\log \mu_{t}-\log \bar{\mu}$ is the deviation of the log of money growth from its central value $\bar{\mu}$,

$$
\begin{gathered}
\phi \equiv-\left.\frac{d \log U^{\prime}\left(c_{A}(\mu)\right)}{d \log \mu}\right|_{\mu=\bar{\mu}}=\left.\sigma \frac{d \log c_{A}(\mu)}{d \log \mu}\right|_{\mu=\bar{\mu}} \\
\left.\eta \equiv \frac{d^{2} \log U^{\prime}\left(c_{A}(\mu)\right)}{(d \log \mu)^{2}}\right|_{\mu=\bar{\mu}}=-\left.\sigma \frac{d^{2} \log c_{A}(\mu)}{(d \log \mu)^{2}}\right|_{\mu=\bar{\mu}} .
\end{gathered}
$$

With this quadratic approximation, we have that the pricing kernel is given by

$$
\log m_{t+1}=\log \beta / \bar{\mu}-(\phi+1) \hat{\mu}_{t+1}+\frac{1}{2} \eta \hat{\mu}_{t+1}^{2}+\phi \hat{\mu}_{t}-\frac{1}{2} \eta \hat{\mu}_{t}^{2} .
$$

Throughout, we assume that the log of home money growth has normal innovations, or shocks, so that

$$
\hat{\mu}_{t+1}=E_{t} \hat{\mu}_{t+1}+\varepsilon_{t+1}
$$

and likewise for foreign money growth. Here $\varepsilon_{t+1}$ and $\varepsilon_{t+1}^{*}$ are the independent shocks across countries and are both normal with mean zero and variance $\sigma_{\varepsilon}^{2}$.

Note for later that in the standard model, since $c_{A}(\mu)$ is constant, $\phi=\eta=0$.

\section{The Model's Implications}

We have developed our general equilibrium monetary model and derived from it a pricing kernel (33). For the rest of the analysis, we use this pricing kernel, together with the driving process for the shocks (34), to work out our model's equilibrium implications for interest rates and exchange rates. We also work through a numerical example which allows us to see that our model's implications are, at least qualitatively, consistent with some patterns of behavior apparent in the data.

\section{A. The Relationship Between Money Growth and Risk Premia}

We begin by using our pricing kernel (33) to show how the risk premium varies systematically with changes in money growth. We show that the risk premium varies even if shocks to money growth have constant conditional variances. In particular, we show that locally a persistent increase in money growth decreases the risk premium $p_{t}$. 
Recall that the risk premium can be written in terms of the pricing kernel as in (28):

$$
p_{t}=\left(\log E_{t} m_{t+1}-E_{t} \log m_{t+1}\right)-\left(\log E_{t} m_{t+1}^{*}-E_{t} \log m_{t+1}^{*}\right) .
$$

Note that if the pricing kernel $m_{t+1}$ were a conditionally lognormal variable, then, as is wellknown, $\log E_{t} m_{t+1}=E_{t} \log m_{t+1}+(1 / 2) \operatorname{var}_{t}\left(\log m_{t+1}\right)$. In such a case, the risk premium $p_{t}$ would equal half the difference of the conditional variances of the log kernels. Given our quadratic approximation (33), however, the pricing kernel is not conditionally lognormal; still, a similar relationship between the risk premium and the conditional variance of the kernel holds.

This relationship is established in the next proposition, the proof of which is in Appendix B. For the resulting risk premium to be well-defined with our quadratic approximation, we need

$$
\eta \sigma_{\varepsilon}^{2}<1
$$

which we assume for the remainder of our analysis. ${ }^{6}$

Proposition 4. Under (33), the risk premium is

$$
p_{t}=\frac{1}{2} \frac{1}{\left(1-\eta \sigma_{\varepsilon}^{2}\right)}\left(\operatorname{var}_{t} \log m_{t+1}-\operatorname{var}_{t} \log m_{t+1}^{*}\right),
$$

where

$$
\operatorname{var}_{t}\left(\log m_{t+1}\right)=\left[-(1+\phi)+\eta E_{t} \hat{\mu}_{t+1}\right]^{2} \sigma_{\varepsilon}^{2}+\frac{3}{4} \eta^{2} \sigma_{\varepsilon}^{4}
$$

and a symmetric formula holds for $\operatorname{var}_{t}\left(\log m_{t+1}^{*}\right)$.

To see how the risk premium varies with money growth, we calculate the derivative of the risk premium and evaluate it at $\mu_{t}=\bar{\mu}$ to get that

$$
\frac{d p_{t}}{d \hat{\mu}_{t}}=-\frac{\eta(\phi+1) \sigma_{\varepsilon}^{2}}{1-\eta \sigma_{\varepsilon}^{2}} \frac{d E_{t} \hat{\mu}_{t+1}}{d \hat{\mu}_{t}} .
$$

Together (36) and (39) imply that the risk premium falls as home money growth rises if $\log c_{A}(\mu)$ is concave in $\log \mu$, so that $\eta>0$, and if money growth is persistent, so that $d E_{t} \hat{\mu}_{t+1} / d \hat{\mu}_{t}$ is positive. Thus, under very simple conditions, we have that the risk premium decreases as the money growth rate increases. 
The idea behind that relationship is as follows. Since $\eta$ is positive, the sensitivity of marginal utility to fluctuations in money growth decreases as expected money growth increases. Since money growth is persistent, a high money growth rate in period $t$ leads households to forecast a higher money growth rate in period $t+1$. Thus, a high money growth rate in period $t$ leads households to predict less variable marginal utility in period $t+1$. Hence, the risk premium in period $t$ decreases as the money growth rate increases in period $t$.

\section{B. The Forward Premium Anomaly}

We now show that this relationship between money growth and risk premia can lead our model to generate the forward premium anomaly - the tendency for high interest rate currencies to appreciate over time. A necessary circumstance is that the persistence of money growth be within an intermediate range.

From the definition of the risk premium (1), we can write the interest rate differential as

$$
i_{t}-i_{t}^{*}=E_{t} \log e_{t+1}-\log e_{t}-p_{t} .
$$

As we have seen, a persistent increase in money growth leads the risk premium $p_{t}$ to fall. When this increase in money growth also leads to an expected exchange rate appreciation smaller than the fall in the risk premium, the interest rate differential increases, and our model generates the forward premium anomaly.

The simplest case to study is when exchange rates are random walks, for then an increase in money growth has no effect on the expected change in the value of the currency. In this case, because the covariance between the interest rate differential and the expected change in the exchange rate is zero, the model generates, at least weakly, the forward premium anomaly.

The more general case is when a persistent increase in money growth leads to an expected exchange rate appreciation. Recall that in standard models without market segmentation, a persistent increase in money growth leads to the opposite: an expected depreciation. Here we discuss in some detail how our model with asset market segmentation delivers different implications for the effects of money growth on the exchange rate. 
To see how an increase in money growth can lead to an expected appreciation of the nominal exchange rate $e_{t}$ in our model, it is helpful to write this expected appreciation as the sum of the expected appreciation of the real exchange rate and the expected inflation differential:

$$
E_{t} \log e_{t+1}-\log e_{t}=\left(E_{t} \log v_{t+1}-\log v_{t}\right)+E_{t}\left[\log \left(P_{t+1} / P_{t}\right)-\log \left(P_{t+1}^{*} / P_{t}^{*}\right)\right]
$$

where the real exchange rate $v_{t}=e_{t} P_{t}^{*} / P_{t}$. In a standard model, an increase in money growth leads to an expected nominal depreciation because the increased money growth increases expected inflation but has no effect on real exchange rates. In our model, an increase in money growth leads to an expected real depreciation that dominates the expected inflation effect. $^{7}$

Using our pricing kernels (21) and (22), our expression for changes in exchange rates (27), and the expression for the home price level together with (16) and its foreign analog, we can write the right side of (41) in terms of the marginal utility of active households:

$$
E_{t}\left[\log U^{\prime}\left(c_{A t+1}^{*}\right) / U^{\prime}\left(c_{A t+1}\right)-\log U^{\prime}\left(c_{A t}^{*}\right) / U^{\prime}\left(c_{A t}\right)\right]+E_{t}\left[\log \mu_{t+1}-\log \mu_{t+1}^{*}\right],
$$

where the first bracketed term corresponds to the change in the real exchange rate and the second to the expected inflation differential. Hence, we can decompose the effect of money growth changes on the expected change in the nominal exchange rate into two parts: a market segmentation effect and an expected inflation effect. The market segmentation effect measures the impact of an increase in money growth on the expected change in the real exchange rate through its impact on the marginal utilities in the first bracketed term in (42). This effect is not present in the standard general equilibrium model, which has no segmentation. The expected inflation effect, which is present in the standard model, measures the impact of an increase in money growth on the expected inflation differential in the second bracketed term in (42).

Now consider the impact of a persistent increase in money growth on the expected change in the nominal exchange rate. The expected inflation effect is simply

$$
d\left(E_{t} \log \mu_{t+1}\right) / d \log \mu_{t} .
$$


This effect is larger the more persistent is money growth. In the standard model, this is the only effect because in that model $c_{A}(\mu)$ is constant (and, hence, $\phi=\eta=0$ ). In the standard model, then, an increase in money growth of one percentage point leads to an expected nominal depreciation of size $d\left(E_{t} \log \mu_{t+1}\right) / d \log \mu_{t}$.

The size of the market segmentation effect depends on both the degree of market segmentation and the persistence of money growth. This follows because a persistent increase in the home money growth rate $\mu_{t}$ affects both the current real exchange rate

$$
\log v_{t}=\log U^{\prime}\left(c_{A}^{*}\left(\mu_{t}^{*}\right)\right) / U^{\prime}\left(c_{A}\left(\mu_{t}\right)\right)
$$

and, by increasing the expected money growth rate in $t+1$, the expected real exchange rate

$$
E_{t} \log v_{t+1}=E_{t} \log U^{\prime}\left(c_{A}^{*}\left(\mu_{t+1}^{*}\right)\right) / U^{\prime}\left(c_{A}\left(\mu_{t+1}\right)\right) .
$$

Using (42), we see that an increase in the home money growth rate $\hat{\mu}_{t}$ leads to an expected change in the real exchange rate of

$$
\frac{d}{d \hat{\mu}_{t}}\left(E_{t} \log v_{t+1}-\log v_{t}\right)=\phi\left[\frac{d\left(E_{t} \hat{\mu}_{t+1}\right)}{d \hat{\mu}_{t}}-1\right],
$$

where we have evaluated this derivative at $\mu_{t}=\bar{\mu}$ and used our quadratic approximation to the marginal utility of active households. ${ }^{8}$

As long as money growth is mean-reverting, in that $d\left(E_{t} \hat{\mu}_{t+1}\right) / d \hat{\mu}_{t}<1$, an increase in money growth near the steady state leads to an expected real appreciation. Clearly, the magnitude of the expected real appreciation depends on both the degree of market segmentation, as measured by $\phi$, and the degree of persistence in money growth, as measured by $d\left(E_{t} \hat{\mu}_{t+1}\right) / d \hat{\mu}_{t}$

Note that the market segmentation effect and the expected inflation effect have opposite signs. If the market segmentation effect dominates, then for values of $\mu_{t}$ close to $\bar{\mu}$, an increase in home money growth leads to an expected appreciation of the nominal exchange rate. This will occur when

$$
\frac{d E_{t} \hat{\mu}_{t+1}}{d \hat{\mu}_{t}} \leq \frac{\phi}{1+\phi}
$$

Now consider how our model can generate the forward premium anomaly. The definition of the risk premium (1) implies that

$$
\frac{d\left(i_{t}-i_{t}^{*}\right)}{d \hat{\mu}_{t}}=\frac{d\left(E_{t} \log e_{t+1}-\log e_{t}\right)}{d \hat{\mu}_{t}}-\frac{d p_{t}}{d \hat{\mu}_{t}} .
$$


To get the forward premium anomaly, we need the impact of money growth on the interest rate differential to have the opposite sign of its impact on expected depreciation. From (39) we know that an increase in money growth drives down the risk premium. Under (47) this increase in money growth generates an expected appreciation of the nominal exchange rate. If the impact of money growth on the risk premium is larger in magnitude than its impact on the exchange rate, then the forward premium anomaly results.

We summarize this discussion in the following proposition:

Proposition 5. If these inequalities are satisfied,

$$
\frac{\phi\left(1-\eta \sigma_{\varepsilon}^{2}\right)}{1+\phi}<\frac{d E_{t} \hat{\mu}_{t+1}}{d \hat{\mu}_{t}} \leq \frac{\phi}{1+\phi},
$$

then for $\mu_{t}$ close to $\bar{\mu}$, a change in money growth leads the interest rate differential and the expected exchange rate depreciation to move in opposite directions.

Proof. Adding (43) and (46) gives that

(50) $\frac{d\left(E_{t} \log e_{t+1}-\log e_{t}\right)}{d \hat{\mu}_{t}}=(1+\phi) \frac{d E_{t} \hat{\mu}_{t+1}}{d \hat{\mu}_{t}}-\phi$.

Adding (39) and (50) gives that

$$
\frac{d\left(i_{t}-i_{t}^{*}\right)}{d \hat{\mu}_{t}}=\frac{1+\phi}{1-\eta \sigma_{\varepsilon}^{2}} \frac{d E_{t} \hat{\mu}_{t+1}}{d \hat{\mu}_{t}}-\phi
$$

The first inequality in (49) implies that $d\left(i_{t}-i_{t}^{*}\right) / d \hat{\mu}$ is positive, so that an increase in money growth increases the interest rate differential. The second inequality in (49) implies that $d\left(E_{t} \log e_{t+1}-\log e_{t}\right) / d \hat{\mu}$ is negative, so that an increase in money growth leads to an expected exchange rate appreciation. Q.E.D.

Note that this proposition implies that our model generates the forward premium anomaly only if money growth has an intermediate level of persistence. This is because to get the anomaly, interest rate differentials and expected changes in exchange rates must move in opposite directions after a money growth shock. Clearly, (47) provides an upper bound on the persistence of money growth, generated by the requirement that the nominal exchange rate be expected to appreciate after a money growth shock. This condition is also the right 
side inequality in (49). The requirement that the movement in the risk premium (39) be larger than the expected depreciation gives the lower bound on the persistence of money growth implied by the left side inequality in (49).

\section{A Numerical Example with Time Series Data}

Now we consider a simple numerical example that demonstrates, at least qualitatively, the model's implications for the movements over time of interest rates and exchange rates and the values of some related variables. Note that we think of this example as simply illustrating some of the behavior our model can generate, rather than as a definitive quantitative analysis of the properties of interest rates and exchange rates. In our example, the endogenous nature of our model's market segmentation is critical for the model to be able to generate much time variation in risk.

\section{Statistics on Interest and Exchange Rates}

We assume that a time period is a month. We let $y=1$ and $\sigma=2$, and we let a fraction $F(0)=.125$ of the households have zero fixed costs $\gamma$ and the remainder have fixed costs with a uniform distribution on $\left[0, \gamma_{\max }\right]$ with $\gamma_{\max }=.1$. Solving equations (19) and (20) for $c_{A}(\mu)$ and $\bar{\gamma}(\mu)$ then gives $\phi=10.9$ and $\eta=1,007$ when $\bar{\mu}$ is equal to $\exp (5 / 1200)$, which is $5 \%$ inflation at an annualized rate.

In Figure $2 \mathrm{~A}$, we plot $\log c_{A}(\mu)$ against $\log \mu$ (annualized). This figure shows that the consumption of active households is increasing and concave in money growth in the relevant range. Because of this nonlinearity, even if the fundamental shocks - here, changes in money growth rates - have constant conditional variances, the resulting pricing kernels do not. Their conditional variances change over time.

The main mechanism through which our model works is that the elasticity of the marginal utility of active households varies with the money growth rate, that is, $\phi(\mu)$ changes with $\mu$. In Figure $2 \mathrm{~B}$ we plot $\phi(\mu)$ against $\log \mu$ (annualized). Clearly $\phi(\mu)$ is falling as $\mu$ increases. From (30) it is clear that this drop in $\phi(\mu)$ reflects the concavity of $\log c_{A}(\mu)$ seen in Figure 2A. (Note that to reconcile the graph of $\phi(\mu)$ with $\eta$ one must recall that $\eta$ is not expressed with $\log \mu$ in annual units but rather in monthly units and the conversion factor is 1200.) In Figure $2 \mathrm{C}$ we plot the fraction of the population that is active against $\log \mu$ 
(annualized). Clearly, this participation rate rises as $\mu$ rises.

Now we use our quadratic approximation to the pricing kernel to illustrate the type of interest rate and exchange rate behavior that our model can generate. We have constructed this example so that the exchange rate is a martingale. Hence, interest rates are driven entirely by movements in the risk premium, and the slope coefficient $b$ in the Fama regression (5) is zero. We now demonstrate that with these features, our model, in addition to generating a slope coefficient similar to that in the data, generates some qualitative properties that are similar to those of the data: interest rate differentials are persistent, and the exchange rate is an order of magnitude more variable than interest rate differentials.

We choose the processes for the money growth rates in this example in order to ensure that the nominal exchange rate follows a random walk (actually, a martingale). Specifically, we choose these processes so that

$$
E_{t} \log e_{t+1}-\log e_{t}=E_{t}\left(\log m_{t+1}^{*}-\log m_{t+1}\right)=0
$$

Since the pricing kernel in each country is a function of only that country's money growth, we choose these processes so that for the home country $E_{t} \log m_{t+1}=\log \beta / \bar{\mu}$, where $\log m_{t+1}$ is given by (33); we do likewise for the foreign country. For both the home and foreign countries, we let these baseline processes be of the form

$$
\hat{\mu}_{t+1}=g\left(\hat{\mu}_{t}\right)+\varepsilon_{t+1}, \hat{\mu}_{t+1}^{*}=g\left(\hat{\mu}_{t}^{*}\right)+\varepsilon_{t+1}^{*}
$$

Because (33) makes $\log m_{t+1}$ a quadratic function in $\mu_{t}$ and $\mu_{t+1}$, the function $g(\cdot)$ that makes the exchange rate a martingale turns out to be quadratic in $\mu_{t}$. To see this, notice that $g(\cdot)$ is obtained by substituting (52) into (33) and setting $E_{t} \log m_{t+1}=\log \beta / \bar{\mu}$. The quadratic equation for $g(\cdot)$ has two solutions; we select the one that implies a mean-reverting process in the sense that $g^{\prime}\left(\hat{\mu}_{t}\right)=d\left(E_{t} \mu_{t+1}\right) / d \hat{\mu}_{t}<1$ when the derivatives are evaluated at $\hat{\mu}_{t}=0$. We let $\varepsilon_{t}$ and $\varepsilon_{t}^{*}$ both be normal with mean zero and standard deviation $\sigma_{\varepsilon}$, and we let the correlation of $\varepsilon_{t}$ and $\varepsilon_{t}^{*}$ be $\rho_{\varepsilon}$.

We use the parameter values $\phi=10$ and $\eta=1,000$ (which we think of as round numbers that are motivated by the calculations above). Here, as before, we assume that a period in the model is a month, and we again let $\bar{\mu}$ correspond to an annualized inflation rate of $5 \%$. We set $\sigma_{\varepsilon}=.0035$ and $\rho_{\varepsilon}=.5 .^{9}$ With these parameters, the resulting money growth 
process of the form (52) is similar to that of an AR(1) process with an autocorrelation of .90. To demonstrate this similarity, in Figure 3 we plot 245 realizations of our baseline money growth process (52) and this $\operatorname{AR}(1)$ process based on the same driving shocks $\varepsilon_{t}$.

Now return to Table 1 . There we have examined some properties of interest rates and exchange rates in the data; here we compare to those data the properties implied by this example. The model's statistics for this example are reported for the slope coefficient $b=0$. These model statistics are computed as the means over 100,000 draws of 245 periods each. The statistics in the data, recall, are averages of the statistics for seven European countries presented by Backus, Foresi, and Telmer (2001), each of which has 245 months of data.

The table shows that in both the data and the model, interest rate differentials do vary, but not as much as changes in the exchange rate. Interest rate differentials are roughly one-third as variable in the model as in the data. But in both the data and the model, changes in the exchange rate have virtually no autocorrelation, whereas interest rate differentials have a high autocorrelation. At a qualitative level, therefore, our model successfully reproduces these features of the data.

\section{Other Time Series Statistics}

Our model also has implications for the disconnect between aggregate consumption and real exchange rates. In this example, aggregate consumption is essentially constant, but real exchange rates are quite variable; hence, real exchange rates are essentially disconnected from fluctuations in aggregate consumption. In this sense, our model is consistent with the Backus-Smith puzzle (Backus and Smith 1993).

As discussed in our 2002 work, another feature of the data is that nominal and real exchange rates have similar volatilities. From (46) and (50), we see that when $\phi$ is large, our model will reproduce that observation. For instance, in our numerical example, the standard deviation of changes in the real exchange rate is about $93 \%$ the size of the standard deviation of changes in the nominal exchange rate.

We also considered an alternative numerical example with the money growth process of the form (52) in which the function $g(\cdot)$ is chosen so that the slope coefficient $b$ in the Fama regression is equal to -1 in population. The statistics for this numerical example, also 
reported in Table 1, are nearly identical to those of the earlier example.

\section{The Role of Endogenous Segmentation}

Now we show that allowing for endogenous segmentation in our model is a critical feature for it to be able to generate substantial amounts of time variation in risk.

In our model, even if segmentation were exogenous, so that the fraction of households that are active were fixed, our model still could generate time-varying risk. This is because the result in Proposition 3 does not depend on the finding of Proposition 2, that more households

pay the fixed cost when money growth increases. Hence, $\log c_{A}(\mu)$ is concave, at least locally, even if the fraction of households that pay the fixed cost does not change with $\mu$. Thus, the same result would hold if segmentation were exogenous.

If segmentation were exogenous, however, the model could not generate much time variation in risk. To see that, suppose that a fraction $F(0)$ of households have zero fixed costs and, hence, are active and that the rest of the households are inactive. For this exogenous segmentation model, it is easy to show that

$$
\phi=\sigma \frac{1-F(0)}{\bar{\mu}-[1-F(0)]} \text { and } \eta=\frac{\bar{\mu}}{\bar{\mu}-[1-F(0)]} \phi \text {. }
$$

Thus, for example, with $\sigma=2$ and $\bar{\mu}=(1.05)^{1 / 12}$, to have $\phi=10$, we need $F(0)=1 / 6$ and, hence, $\eta=60$. This value of $\eta$ is an order of magnitude smaller than the value generated by our endogenous segmentation model. As we show in Table 1 in the row labeled With Exogenous Segmentation, when we simulate interest rates and exchange rates with these new values of $\phi$ and $\eta$, choosing money growth to ensure that exchange rates follow a random walk, we find that interest rates barely fluctuate. In particular, the standard deviation of the interest rate differential from the model is one one-hundredth of that in the data.

Note, finally, that with $F(0)=1$, so that all households are always active, the model reduces to the standard constant velocity cash-in-advance model with no time variation in risk.

\section{Long-Run Averages}

So far we have focused on the implications of our model for fluctuations over time in the interest rate differential and the exchange rate for a single pair of currencies. We have 
shown that our model can generate the forward premium anomaly, or the observation that high interest rate currencies tend to appreciate over time. The data on long-run averages of interest rate differentials and exchange rate changes in a cross section of currencies tend to show the opposite pattern as the time series data: currencies that have high interest rates on average tend to depreciate on average. (See, for example, Backus, Foresi, and Telmer 2001.) Here we document that and then show that our model is qualitatively consistent with this feature of the data as well.

To document this feature, we use monthly data on 14 countries kindly provided by Ravi Bansal and Magnus Dahlquist. We use these data for the period from January 1976 to March 1998 to construct average one-month interest rate differentials between the U.S. rate and each of the other countries' rate as well as corresponding averages of exchange rate changes over the period.

Figure 4A displays a scatterplot of the resulting values. It shows a clear positive relationship between the averages, with a slope close to 1 .

Our model is consistent with this cross section observation. To see that, suppose we have a collection of countries with differing permanent components of their money growth rates $\bar{\mu}_{i}$ that, in annualized terms, vary between $1 \%$ and $12 \%$ per year. For each of these countries, we use values for the fixed costs and the risk aversion parameter from our numerical examples to compute the implied values of $\phi_{i}$ and $\eta_{i}$. We then construct money growth processes, indexed by $g_{i}\left(\mu_{t}\right)$ as before, so that for each country $i, E_{t} \log m_{i t+1}=\log \beta / \bar{\mu}_{i}$, where $\log m_{i t+1}$ is the pricing kernel for country $i$. We then simulate 100,000 samples of length 245 for these countries and compute the average interest rate differential and exchange rate change relative to our baseline country, which has the permanent component of its money growth equal to $5 \%$ on an annualized basis.

In Figure 4B we plot the resulting average exchange rate changes against the average interest rate differentials. Comparing Figures $4 \mathrm{~A}$ and $4 \mathrm{~B}$, we see that our model is consistent with the cross section observation that over the long run, currencies of countries that have high interest rates on average tend to depreciate on average.

Of course, the standard model with no segmentation is consistent with this cross section data as well. Unlike the standard model, however, our model can generate these 
long-run averages while at the same time generating the time series patterns of interest and exchange rates that underlie the forward premium anomaly.

\section{Conclusion}

We have constructed a simple, general equilibrium monetary model with endogenously segmented asset markets and have shown that this sort of friction may be a critical feature of a complete model of interest rates and exchange rates. The fundamental challenge behind this exercise has been to develop a model in which exchange rates roughly follow a random walk (so that expected changes in exchange rates are roughly constant) while interest rate differentials are highly variable and persistent. In such a model, by definition, movements in

interest rate differentials are movements in risk. Our main contribution here is to propose a mechanism through which that risk changes because of changes in monetary policy. 


\section{Appendix A: An Extension with Trade in Goods}

In the work above, we have kept the model simple by abstracting from the possibility of trade in goods. Here we sketch out a version of the model with trade in goods that works similarly to the original model. Essentially we take the models of Helpman and Razin (1982) and Lucas (1982) and extend them to have fixed costs of accessing asset markets. We demonstrate that this extended model leads to results similar to those in the simple model. (Note that in our economy we assume that goods are purchased in the sellers' currency. An alternative assumption is that goods are purchased in the buyers' currency. For a discussion of the role of these alternative assumptions, see Helpman and Razin 1984.)

In this extended model, let there be two goods $h$ and $f$, referred to as home and foreign goods. Households in the home country have endowments $y_{h}$ and $y_{f}$ of these goods, while households in the foreign country have endowments $y_{h}^{*}$ and $y_{f}^{*}$. Home country households have an additively separable period utility function over these goods

$$
\alpha U\left(c_{h}\right)+(1-\alpha) U\left(c_{f}\right),
$$

where $\alpha \in(0,1]$ and $\left(c_{h}, c_{f}\right)$ denotes the consumption of the home and foreign goods by the home households. Foreign households have a similar period utility function

$$
\alpha U\left(c_{f}^{*}\right)+(1-\alpha) U\left(c_{h}^{*}\right),
$$

where $\left(c_{h}^{*}, c_{f}^{*}\right)$ denotes the consumption of the home and foreign goods. When $\alpha \geq 1 / 2$, preferences exhibit a type of home bias: home country households consume relatively more home goods, and foreign households, relatively more foreign goods.

As in Helpman and Razin (1982) and Lucas (1982), home goods must be purchased with home currency and foreign goods with foreign currency. Specifically, households in each country have one cash-in-advance constraint for purchases of home goods and one for purchases of foreign goods. Home households have a fixed cost $\gamma$ that applies to each transfer of home currency between the home goods market and the asset market, and a separate fixed $\operatorname{cost} \gamma^{*}$ that applies to each transfer of foreign currency between the foreign goods market and the asset market. Home households are indexed by $\left(\gamma, \gamma^{*}\right)$, which we assume have joint distribution given by $F(\gamma) F^{*}\left(\gamma^{*}\right)$. Foreign households are indexed by a symmetric distribution 
of costs: $F(\gamma)$ for transfers between foreign goods markets and the asset market and $F^{*}\left(\gamma^{*}\right)$ for transfers between home goods markets and the asset market.

In the model, households now have more options of participation in the goods and asset markets. They can transfer only home currency, only foreign currency, both currencies, or none at all. For these different patterns of transfer, the home households will pay $\gamma, \gamma^{*}, \gamma+\gamma^{*}$, and 0 , respectively, while the foreign households will pay $\gamma^{*}, \gamma, \gamma^{*}+\gamma$, and 0 , respectively. It can be shown that the equilibrium allocations of home goods solve the following planning problem that is the obvious generalization of the one in the simpler model without trade in goods:

$$
\begin{aligned}
\max _{c_{h A}, c_{h A}^{*} \cdot \bar{\gamma}_{h}, \bar{\gamma}_{h}^{*}} \alpha U\left(c_{h A}\right) F\left(\bar{\gamma}_{h}\right)+\alpha U\left(y_{h} / \mu\right)\left[1-F\left(\bar{\gamma}_{h}\right)\right] \\
+(1-\alpha) U\left(c_{h A}^{*}\right) F^{*}\left(\bar{\gamma}_{h}^{*}\right)+(1-\alpha) U\left(y_{h}^{*} / \mu\right)\left[1-F^{*}\left(\bar{\gamma}_{h}^{*}\right)\right]
\end{aligned}
$$

subject to

$$
\begin{aligned}
& c_{h A} F\left(\bar{\gamma}_{h}\right)+\int_{0}^{\bar{\gamma}_{h}} \gamma f(\gamma) d \gamma+\left[1-F\left(\bar{\gamma}_{h}\right)\right] y_{h} / \mu \\
& +c_{h A}^{*} F^{*}\left(\bar{\gamma}_{h}^{*}\right)+\int_{0}^{\bar{\gamma}_{h}^{*}} \gamma f^{*}(\gamma) d \gamma+\left[1-F^{*}\left(\bar{\gamma}_{h}^{*}\right)\right] y_{h}^{*} / \mu=y_{h}+y_{h}^{*} .
\end{aligned}
$$

Here we denote the consumption of home goods by the home and foreign households by $c_{h A}$ and $c_{h A}^{*}$. We also denote the cutoff values for transferring home currency to the home goods market by the home and foreign households by $\bar{\gamma}_{h}$ and $\bar{\gamma}_{h}^{*}$. The equilibrium allocations of foreign goods solve a similar problem.

The solution to the problem for home goods is similar to the simpler problem in which goods are not tradable. The link between money injections and households' marginal utilities is also similar. The key distinctions between the model with and without tradable goods are as follows. Here all active households equate their marginal utilities; hence, the consumption of home goods of home and foreign active households moves together. If a home household does not make a transfer of home currency, then the home consumption of home goods is $c_{h}=y_{h} / \mu$. If a foreign household does not make a transfer of home currency, then its consumption of the home good is $c_{h}^{*}=y_{h}^{*} / \mu$. Hence, the value of making a transfer of home currency for a home household differs from that of making one for a foreign household. 
Likewise, the cost of making such a transfer is drawn from $F(\gamma)$ for a home household and from $F^{*}\left(\gamma^{*}\right)$ for a foreign household. Because of these differences in the value and costs of making transfers, in general, the home households have a cutoff function for transfers of home currency $\bar{\gamma}_{h}(\mu)$ which differs from the cutoff that foreign households have for transfers of home currency $\bar{\gamma}_{h}^{*}(\mu)$. A similar distinction holds with respect to foreign currency transfers.

Consider now a utility function of the form $U(c)=c^{1-\sigma} /(1-\sigma)$. It is easy to show that the optimal allocations $\left\{c_{h A}(\mu), c_{h A}^{*}(\mu), \bar{\gamma}_{h}(\mu), \bar{\gamma}_{h}^{*}(\mu)\right\}$ are increasing functions of $\mu$ and that the consumption of home goods of the home and foreign active households are proportional, $c_{h A}^{*}(\mu)=\omega c_{h A}(\mu)$, where $\omega=[(1-\alpha) / \alpha]^{\frac{1}{\sigma}}$.

Next we present a proposition in which the determination of the active households' consumption and cutoff function is identical to that in the model without tradable goods.

Proposition 8. Assume that endowments satisfy

$$
y_{h}^{*} / y_{h}=\omega
$$

and that the upper bound of the support for $\gamma$, denoted $\gamma_{\max }$, satisfies $F^{*}\left(\omega \gamma_{\max }\right)=1$. Then $\bar{\gamma}_{h}(\mu)$ and $\bar{\gamma}_{h}^{*}(\mu)$ satisfy $\bar{\gamma}_{h}^{*}(\mu)=\omega \bar{\gamma}_{h}(\mu)$, and the values of $c_{h A}(\mu)$ and $\bar{\gamma}_{h}(\mu)$ are identical to those in an economy with no tradable goods, an aggregate endowment of $y_{h}+y_{h}^{*}$, and a distribution of costs given by

$$
\tilde{F}(\gamma)=\frac{F(\gamma)+\omega F^{*}(\omega \gamma)}{1+\omega} .
$$

The proof of this proposition follows from verifying that the candidate solution satisfies the first-order conditions of the problem stated above. The assumption (54) includes the case of completely symmetric countries, $\alpha=1 / 2$ and $y_{h}=y_{h}^{*}$, but it is more general. In particular, this assumption allows for a type of home bias preference of $\alpha \geq 1 / 2$ and specialization in the endowments in the sense of $y_{h}>y_{h}^{*}$. The home bias implies that $c_{h} \geq c_{f}$ at $\mu=\mu^{*}$. This assumption implies that for $\mu=1$, exports are zero, since $c_{h}=y_{h}$. For $\mu>1$, however, there typically will be trade in equilibrium, provided that $F$ and $F^{*}$ differ.

When assumption (54) is not satisfied, $\bar{\gamma}_{h}$ and $\bar{\gamma}_{h}^{*}$ move together with $\mu$, but they are not necessarily proportional; hence, the expression of $c_{h A}(\mu)$ does not reduce exactly to that 
of the model with no tradable goods. Nevertheless, the expressions for $c_{h A}$ and $\bar{\gamma}_{h}$ are similar to those in that model.

To see why, consider the extreme case in which $y_{h}^{*}=0$, so that the foreign country has no endowment of the home good. In this case, under appropriate conditions, all foreign households engage in transfers of home currency, so that $\bar{\gamma}_{h}^{*}(\mu)=\gamma_{\max }^{*}$. The resulting expressions for $c_{h A}(\mu)$ and $\bar{\gamma}_{h}(\mu)$ correspond to those for the model with no tradable goods, the cost functions $\tilde{F}(\gamma)=[F(\gamma)+\omega] /(1+\omega)$ and $\tilde{F}(0)=\omega /(1+\omega)$, the consumption of inactive home households $y_{h} / \mu$, and the aggregate endowment $\left[y_{h}-\int \gamma^{*} d F^{*}\left(\gamma^{*}\right)\right] /(1+\omega)$.

\section{Appendix B: Some Proofs}

\section{Proof of Unique Solution (Requirement for Proposition 1)}

Here we show that equations (19) and (20) have at most one solution for any given $\mu$.

To see this result, solve for $\bar{\gamma}$ as a function of $c_{A}$ from (20) and suppress explicit dependence of $\mu$ to get

$$
\bar{\gamma}\left(c_{A}\right)=\frac{U\left(c_{A}\right)-U(y / \mu)}{U^{\prime}\left(c_{A}\right)}-\left[c_{A}-(y / \mu)\right] .
$$

Note that

$$
\frac{d \bar{\gamma}\left(c_{A}\right)}{d c_{A}}=-\frac{U^{\prime \prime}\left(c_{A}\right)}{\left[U^{\prime}\left(c_{A}\right)\right]^{2}}\left[U\left(c_{A}\right)-U(y / \mu)\right] .
$$

Use (20) to see that $d \bar{\gamma}\left(c_{A}\right) / d c_{A}$ is positive when $c_{A}+\bar{\gamma}-(y / \mu)>0$ and negative when $c_{A}+\bar{\gamma}-(y / \mu)<0$. Substituting $\bar{\gamma}\left(c_{A}\right)$ into (19) and differentiating the left side of the resulting expression with respect to $c_{A}$ gives

$$
F\left(\bar{\gamma}\left(c_{A}\right)\right)+\left[c_{A}+\bar{\gamma}\left(c_{A}\right)-(y / \mu)\right] \frac{d \bar{\gamma}\left(c_{A}\right)}{d c_{A}}
$$

Using (55), we see that (56) is strictly positive; hence, the equations have at most one solution. Q.E.D.

\section{Proof of Proposition 2}

Differentiating equations (19) and (20) with respect to $\mu$ and solving for $\bar{\gamma}^{\prime}$ gives that

$$
\bar{\gamma}^{\prime}(\mu)=\frac{\left[U^{\prime}(y / u)-U^{\prime}\left(c_{A}\right)\right](y / \mu)-U^{\prime \prime}\left(c_{A}\right)\left[c_{A}+\bar{\gamma}-(y / \mu)\right] \frac{1-F}{F} y / \mu^{2}}{U^{\prime}\left(c_{A}\right)-U^{\prime \prime}\left(c_{A}\right)\left[c_{A}+\bar{\gamma}-(y / \mu)\right] f / F},
$$


where to simplify we have omitted the arguments in the functions $F, f, c_{A}$, and $\bar{\gamma}$. Note that $c_{A}(1)=y$ and $\bar{\gamma}(1)=0$. Also note that (19) implies that if $\mu>1$, then $c_{A}+\bar{\gamma}-(y / \mu)>0$. To derive this result, rewrite (19) as

$$
c_{A}(\mu)+\frac{\int_{0}^{\bar{\gamma}(\mu)} \gamma f(\gamma) d \gamma}{F(\bar{\gamma}(\mu))}-y / \mu=\frac{y-y / \mu}{F(\bar{\gamma}(\mu))},
$$

use the inequality $\bar{\gamma}(\mu) \geq\left(\int_{0}^{\bar{\gamma}(\mu)} \gamma f(\gamma) d \gamma\right) / F(\bar{\gamma}(\mu))$, and note that the right side of (57) is strictly positive for $\mu>1$. It follows from this result and (20) that $U^{\prime}(y / \mu)-U^{\prime}\left(c_{A}\right)>0$ for $\mu>1$. Finally, since $U$ is strictly concave, $U^{\prime \prime}\left(c_{A}\right)<0$; thus, $\bar{\gamma}^{\prime}>0$ for $\mu>1$. Using similar results for $\mu=1$, we get that $\gamma^{\prime}(1)=0$. Q.E.D.

\section{Proof of Proposition 3}

We first show that $\phi(1)=\sigma[1-F(0)] / F(0)$, which is positive when $F(0)>0$. To see this, differentiate (19) with respect to $\mu$ and $\bar{\gamma}$, and use, from Proposition 2 , that $\bar{\gamma}^{\prime}(1)=\bar{\gamma}(1)=0$ in order to get that

$$
c_{A}^{\prime}(1)=y \frac{1-F(0)}{F(0)} .
$$

Using this expression for $c_{A}^{\prime}(1)$ and using $c_{A}(1)=y$ in $\phi(1)=\sigma c_{A}^{\prime}(1) / c_{A}(1)$ gives our intended result.

We next show that $\phi^{\prime}(1)=-\phi(1) / F(0)$, which is negative because $\phi(1)>0$ and $F(0)>0$. To see this, first differentiate $(30)$ to get that

$$
\phi^{\prime}(1)=\sigma\left[\frac{c_{A}^{\prime \prime}(1)}{c_{A}(1)}+\frac{c_{A}^{\prime}(1)}{c_{A}(1)}-\left(\frac{c_{A}^{\prime}(1)}{c_{A}(1)}\right)^{2}\right] .
$$

Second, differentiate (19) with respect to $\mu$ and $\bar{\gamma}$, and use the result at $\mu=1, \bar{\gamma}^{\prime}(\mu)=$ $\bar{\gamma}(\mu)=0$, and $c_{A}(\mu)+\bar{\gamma}(\mu)-y / \mu=0$ to get that

$$
c_{A}^{\prime \prime}(1)=-2 y \frac{1-F(0)}{F(0)} .
$$

Using these expressions for $c_{A}^{\prime}$ and $c_{A}^{\prime \prime}$ in (58) produces the desired result. Q.E.D.

\section{Proof of Proposition 4}

To prove Proposition 4, we derive two equations, (37) and (38). 
To derive (37), start with (35), the risk premium defined in terms of the pricing kernels. Compute $E_{t} \log m_{t+1}$ from (33). To compute $\log E_{t} m_{t+1}$, we must compute

$$
\log E_{t} \exp \left(\left[-(\phi+1)+\eta E_{t} \hat{\mu}_{t+1}\right] \varepsilon_{t+1}+\frac{\eta}{2} \varepsilon_{t+1}^{2}\right)
$$

To do that, use the result that if $x$ is normally distributed with mean zero and variance $\sigma^{2}$ and satisfies $1-2 b \sigma^{2}>0$, then

$$
E \exp \left(a x+b x^{2}\right)=\exp \left(\frac{1}{2} \frac{a^{2} \sigma^{2}}{\left(1-2 b \sigma^{2}\right)}\right)\left(\frac{1}{1-2 \sigma^{2} b}\right)^{1 / 2} .
$$

To derive (59), note that

$$
\begin{aligned}
& E \exp \left(a x+b x^{2}\right)=\frac{1}{\sigma \sqrt{2 \pi}} \int \exp \left(a x+b x^{2}\right) \exp \left(-\frac{x^{2}}{2 \sigma^{2}}\right) d x= \\
& \frac{1}{\sigma \sqrt{2 \pi}} \int \exp \left(\frac{1}{2 \sigma^{2}}\left[2 \sigma^{2} a x+\left(2 \sigma^{2} b-1\right) x^{2}\right]\right) d x= \\
& \frac{1}{\sigma \sqrt{2 \pi}} \int \exp \left(\frac{1}{2 \sigma^{2}}\left[-\left(1-2 \sigma^{2} b\right) x^{2}+2 \sigma^{2} a x-\left(\frac{\sigma^{4} a^{2}}{1-2 \sigma^{2} b}\right)+\left(\frac{\sigma^{4} a^{2}}{1-2 \sigma^{2} b}\right)\right]\right) d x= \\
& \exp \left(\frac{1}{2} \frac{a^{2} \sigma^{2}}{\left(1-2 b \sigma^{2}\right)}\right) \frac{1}{\sigma \sqrt{2 \pi}} \int \exp \left(-\frac{1}{2 \sigma^{2}}\left[\left(1-2 \sigma^{2} b\right)^{1 / 2} x-\frac{\sigma^{2} a}{\left(1-2 \sigma^{2} b\right)^{1 / 2}}\right]^{2}\right) d x= \\
& \exp \left(\frac{1}{2} \frac{a^{2} \sigma^{2}}{\left(1-2 b \sigma^{2}\right)}\right) \frac{1}{\sigma \sqrt{2 \pi}} \int \exp \left(-\frac{\left(1-2 \sigma^{2} b\right)}{2 \sigma^{2}}\left[x-\frac{\sigma^{2} a}{\left(1-2 \sigma^{2} b\right)}\right]^{2}\right) d x .
\end{aligned}
$$

which equals (59).

We can derive (38) using (33) together with the standard results that $E_{t} \varepsilon_{t+1}^{4}=3 \sigma_{\varepsilon}^{4}$ and $E_{t} \varepsilon_{t+1}^{3}=0$. Q.E.D. 


\section{Notes}

${ }^{1}$ Technically, $p_{t}$ is simply the log of the excess return on foreign currency bonds. In general, this excess return could arise for many reasons, including differences in taxes, liquidity services, or transaction costs across bonds. We take the view here that fluctuations in this excess return are driven primarily by risk; hence, we refer to the excess return as the risk premium.

${ }^{2}$ The forward premium anomaly can also be stated in terms of forward exchange rates. The forward exchange rate $f_{t}$ is the price specified in a contract in period $t$ in which the buyer has the obligation to transfer $f_{t}$ dollars in $t+1$ in exchange for one euro. The forward premium is then the forward rate relative to the spot rate $f_{t} / e_{t}$. Arbitrage implies that $\log f_{t}-\log e_{t}=i_{t}-i_{t}^{*}$. Thus, (3) can be restated as $\operatorname{cov}\left(\log f_{t}-\log e_{t}, \log e_{t+1}-\log e_{t}\right)<0$. The forward premium and the expected change in exchange rates, therefore, tend to move in opposite directions. This observation contradicts the hypothesis that the forward rate is a good predictor of the future exchange rate.

${ }^{3}$ To see that (4) implies (6), use (1) to rewrite (4) as $\operatorname{var}\left(i_{t}-i_{t}^{*}\right)+\operatorname{cov}\left(i_{t}-i_{t}^{*}, p_{t}\right) \leq 0$ or

$$
\operatorname{var}\left(i_{t}-i_{t}^{*}\right) \leq-\operatorname{cov}\left(i_{t}-i_{t}^{*}, p_{t}\right)=-\operatorname{corr}\left(i_{t}-i_{t}^{*}, p_{t}\right) \operatorname{std}\left(i_{t}-i_{t}^{*}\right) \operatorname{std}\left(p_{t}\right)
$$

Then, as does Fama (1984), divide by $\operatorname{std}\left(i_{t}-i_{t}^{*}\right)$, and use the fact that a correlation is less than or equal to one in absolute value.

${ }^{4}$ It is easy to see that if we replace the assumption that each household draws its fixed cost once with the assumption that each household takes an i.i.d. draw of its fixed cost each period, the analysis is identical.

${ }^{5}$ Recall our assumptions that a complete set of nominal claims are traded in the asset market and that agents face a fixed cost of transferring cash between the asset market and the goods market. These assumptions imply that we do not have a complete set of contingent claims to consumption. Because of the fixed cost, households choose to bear some consumption risk endogenously. 
${ }^{6}$ This condition ensures that $E_{t} m_{t+1}$ exists. In Appendix B, in the proof of Proposition 4 , we need the generalization of this condition: $1-2 b \sigma^{2}>0$. In the proof, when we compute

$$
\int \exp \left(-\left(1-2 b \sigma^{2}\right) x^{2}\right) d x
$$

we need this condition to have this integral well-defined.

${ }^{7}$ Note that in both our segmented market model and the standard model, when today's money growth rate increases, today's exchange rate depreciates. In the segmented market model, this initial depreciation is so large that it leads to overshooting, in that after the impact period, the exchange rate appreciates. In the standard model, this initial depreciation is small, and hence, it leads to undershooting, in that after the impact period, the exchange continues to depreciate.

${ }^{8}$ Doing so gives that the expected depreciation of the real exchange rate is given by

$$
\begin{aligned}
& E_{t} \log v_{t+1}-\log v_{t}= \\
& -\phi E_{t}\left(\hat{\mu}_{t+1}^{*}-\hat{\mu}_{t+1}\right)+\frac{1}{2} \eta E_{t}\left(\hat{\mu}_{t+1}^{* 2}-\hat{\mu}_{t+1}^{2}\right)+\phi\left(\hat{\mu}_{t}^{*}-\hat{\mu}_{t}\right)-\frac{1}{2} \eta\left(\hat{\mu}_{t}^{* 2}-\hat{\mu}_{t}^{2}\right) .
\end{aligned}
$$

${ }^{9}$ See Brandt, Cochrane, and Santa-Clara (2006) for a discussion of the correlation of home and foreign pricing kernels needed to explain the data. 


\section{References}

Allen, Franklin, and Douglas Gale. 1994. Limited market participation and volatility of asset prices. American Economic Review 84 (4, September): 933-55.

Alvarez, Fernando, and Andrew Atkeson. 1997. Money and exchange rates in the Grossman-Weiss-Rotemberg model. Journal of Monetary Economics 40 (3, December): 61940.

Alvarez, Fernando, Andrew Atkeson, and Chris Edmond. 2003. On the sluggish response of prices to money in an inventory-theoretic model of money demand. NBER Working Paper 10016.

Alvarez, Fernando, Andrew Atkeson, and Patrick J. Kehoe. 2002. Money, interest rates, and exchange rates with endogenously segmented markets. Journal of Political Economy 110 (1, February): 73-112.

Alvarez, Fernando, and Urban J. Jermann. 2001. Quantitative asset pricing implications of endogenous solvency constraints. Review of Financial Studies 14 (4, Winter): $1117-51$.

Backus, David K., Silverio Foresi, and Chris I. Telmer. 1995. Interpreting the forward premium anomaly. Canadian Journal of Economics 28 (Special issue, November): S108-19.

Backus, David K., Silverio Foresi, and Chris I. Telmer. 2001. Affine term structure models and the forward premium anomaly. Journal of Finance 56 (1, February): 279-304.

Backus, David K., Allan W. Gregory, and Chris I. Telmer. 1993. Accounting for forward rates in markets for foreign currency. Journal of Finance 48 (5, December): 18871908.

Backus, David K., and Gregor W. Smith. 1993. Consumption and real exchange rates in dynamic economies with non-traded goods. Journal of International Economics 35 (3-4, November): 297-316.

Bansal, Ravi, and Magnus Dahlquist. 2000. The forward premium puzzle: Different tales from developed and emerging economies. Journal of International Economics 51 (1, June): 115-44.

Bansal, Ravi, A. Ronald Gallant, Robert Hussey, and George Tauchen. 1995. Nonparametric estimation of structural models for high-frequency currency market data. Journal 
of Econometrics 66 (1-2, March-April): 251-87.

Bansal, Ravi and Ivan Shaliastovich. 2007. Risk and return in bond, currency, and equity markets. Manuscript, Duke University.

Basak, Suleyman, and Domenico Cuoco. 1998. An equilibrium model with restricted stock market participation. Review of Financial Studies 11 (2, Summer): 309-41.

Baumol, William J. 1952. The transactions demand for cash: An inventory theoretic approach. Quarterly Journal of Economics 66 (4, November): 545-56.

Bekaert, Geert. 1996. The time variation of risk and return in foreign exchange markets: A general equilibrium perspective. Review of Financial Studies 9 (2, Summer): $427-70$.

Brandt, Michael W., John H. Cochrane, and Pedro Santa-Clara. 2006. International risk sharing is better than you think, or exchange rates are too smooth. Journal of Monetary Economics 53, (4, May): 671-98.

Brav, Alon, George M. Constantinides, and Christopher C. Geczy. 2002. Asset pricing with heterogeneous consumers and limited participation: Empirical evidence. Journal of Political Economy 110 (4, August): 793-824.

Campbell, John Y., and John H. Cochrane. 1999. By force of habit: A consumptionbased explanation of aggregate stock market behavior. Journal of Political Economy 107 (2, April): 205-51.

Canova, Fabio, and Jane Marrinan. 1993. Profits, risk, and uncertainty in foreign exchange markets. Journal of Monetary Economics 32 (2, November): 259-86.

Cochrane, John H. 2001. Asset Pricing. Princeton, N.J.: Princeton University Press. Engel, Charles. 1996. The forward discount anomaly and the risk premium: A survey of recent evidence. Journal of Empirical Finance 3 (2, June): 123-92.

Fama, Eugene F. 1984. Forward and spot exchange rates. Journal of Monetary Economics 14 (3, November): 319-38.

Fuerst, Timothy S. 1992. Liquidity, loanable funds, and real activity. Journal of Monetary Economics 29 (1, February): 3-24.

Grilli, Vittorio, and Nouriel Roubini. 1992. Liquidity and exchange rates. Journal of International Economics 32 (3-4, May): 339-52. 
Hansen, Lars Peter, and Ravi Jagannathan. 1991. Implications of security market data for models of dynamic economies. Journal of Political Economy 99 (2, April): 225-62.

Helpman, Elhanan, and Assaf Razin. 1982. Dynamics of a floating exchange rate regime. Journal of Political Economy 90 (4, August): 728-54.

Helpman, Elhanan, and Assaf Razin. 1984. The role of saving and investment in exchange rate determination under alternative monetary mechanisms. Journal of Monetary Economics 13 (3, May): 307-25.

Hodrick, Robert J. 1987. The Empirical Evidence on the Efficiency of Forward and Futures Foreign Exchange Markets. Chur, Switz.: Harwood Academic Publishers.

Hodrick, Robert J. 1989. Risk, uncertainty, and exchange rates. Journal of Monetary Economics 23 (3, May): 433-59.

Khan, Aubhik, and Julia K. Thomas. 2007. Inflation and interest rates with endogenous market segmentation. Working Paper 07-1, Federal Reserve Bank of Philadelphia.

Lucas, Robert E., Jr. 1982. Interest rates and currency prices in a two-country world. Journal of Monetary Economics 10 (3, November): 335-59.

Lucas, Robert E., Jr. 1990. Liquidity and interest rates. Journal of Economic Theory 50 (2, April): 237-64.

Lustig, Hanno, and Stijn Van Nieuwerburgh. 2005. Quantitative asset pricing implications of housing collateral constraints. Manuscript, University of California, Los Angeles.

Lustig, Hanno, and Adrien Verdelhan. 2007. The cross section of foreign currency risk premia and consumption growth risk. American Economic Review 97 (1, March): 89-117.

Mankiw, N. Gregory, and Stephen P. Zeldes. 1991. The consumption of stockholders and nonstockholders. Journal of Financial Economics 29 (1, March): 97-112.

Mehra, Rajnish, and Edward C. Prescott. 1985. The equity premium: A puzzle. Journal of Monetary Economics 15 (2, March): 145-61.

Obstfeld, Maurice, and Kenneth Rogoff. 1996. Foundations of International Macroeconomics. Cambridge, Mass.: MIT Press.

Obstfeld, Maurice, and Kenneth Rogoff. 2001. Risk and exchange rates. Manuscript, University of California, Berkeley. 
Rotemberg, Julio J. 1985. Money and the terms of trade. Journal of International Economics 19 (1-2, August): 141-60.

Schlagenhauf, Don E., and Jeffrey M. Wrase. 1995. Liquidity and real activity in a simple open economy model. Journal of Monetary Economics 35 (3, August): 431-61.

Tobin, James. 1956. The interest-elasticity of transactions demand for cash. Review of Economics and Statistics 38 (3, August): 241-47.

Vissing-Jorgensen, Annette. 2002. Limited asset market participation and the elasticity of intertemporal substitution. Journal of Political Economy 110 (4, August): 825-53. 


\section{Figure 1 Timing in the Two Markets for a Household in the Home Country}

\section{Asset Market}

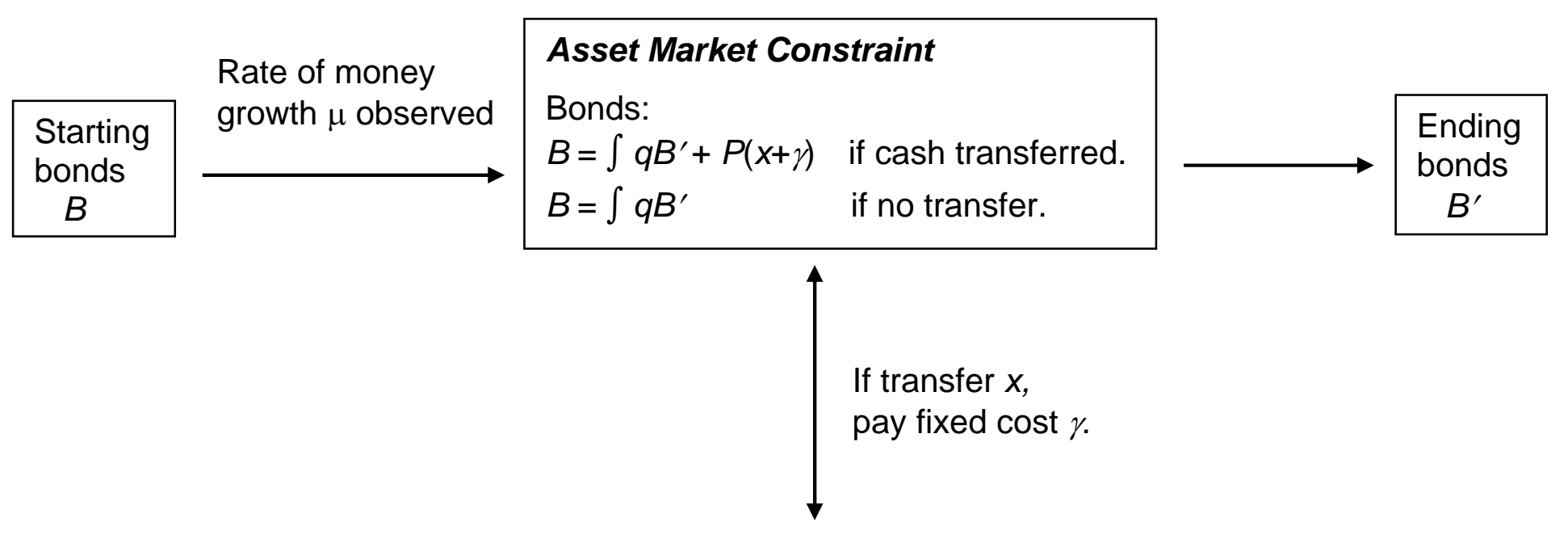

Goods Market
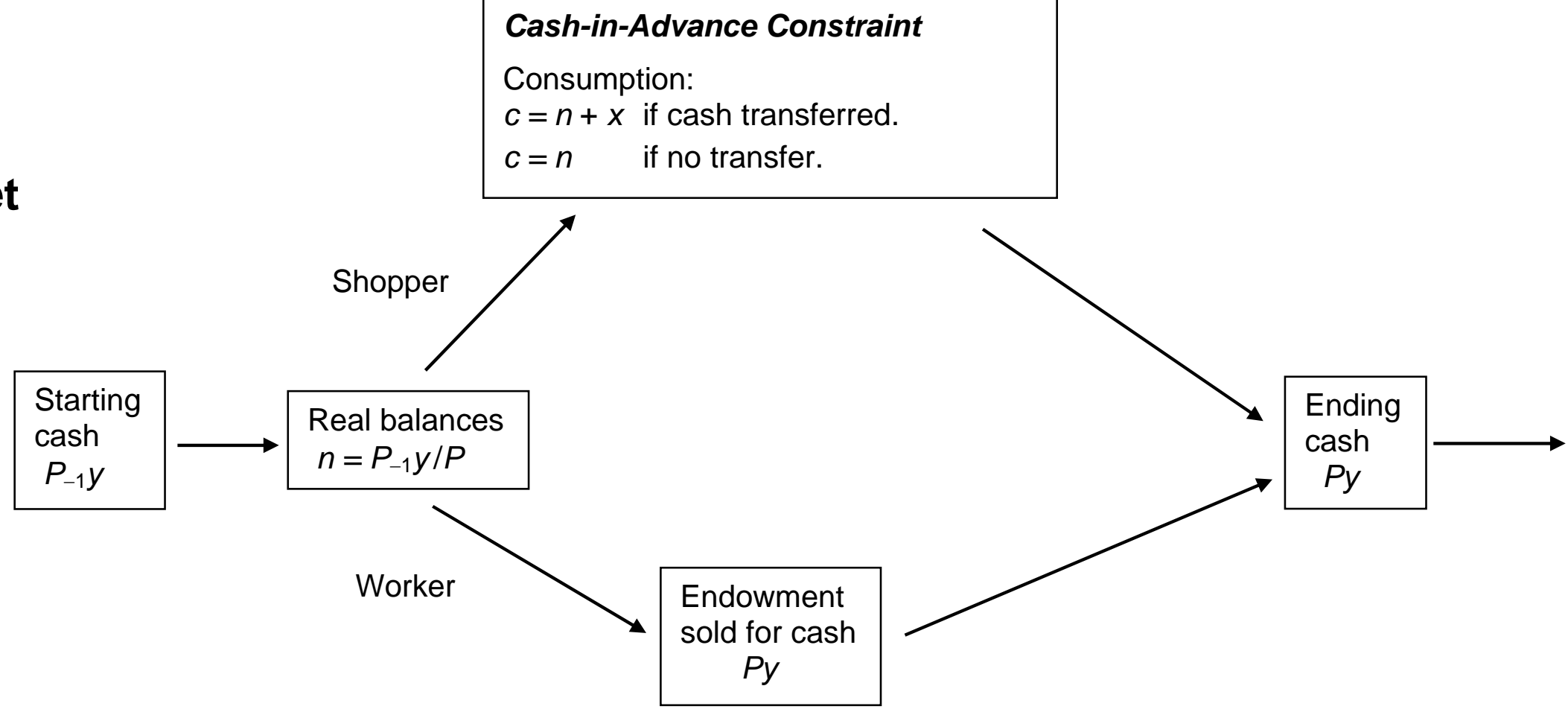
Figure 2A How the Log of the Consumption of Active Households Is Related to the Log of Money Growth

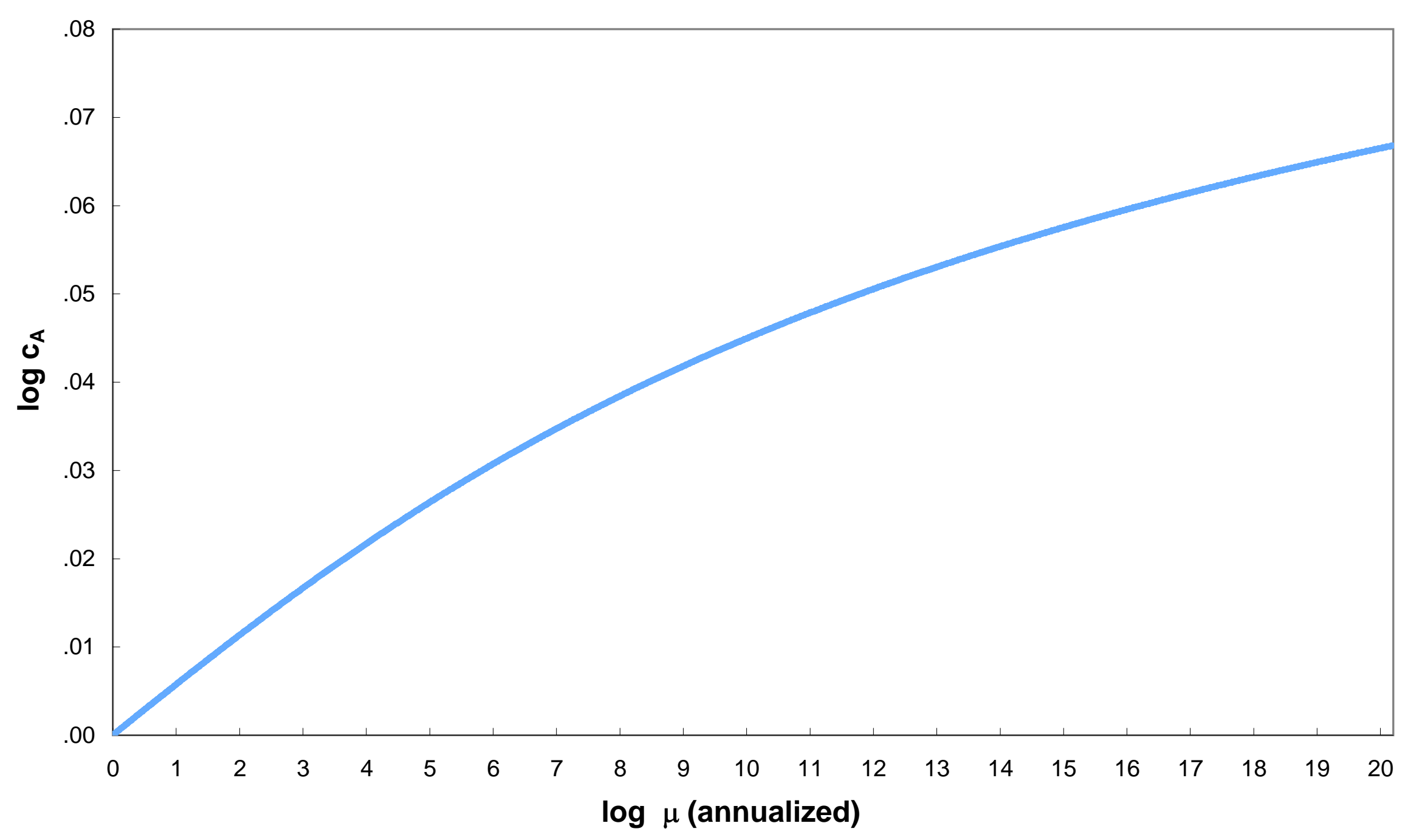


Figure 2B How the Elasticity of Marginal Utility $\phi(\mu)$ Is Related to the Log of Money Growth

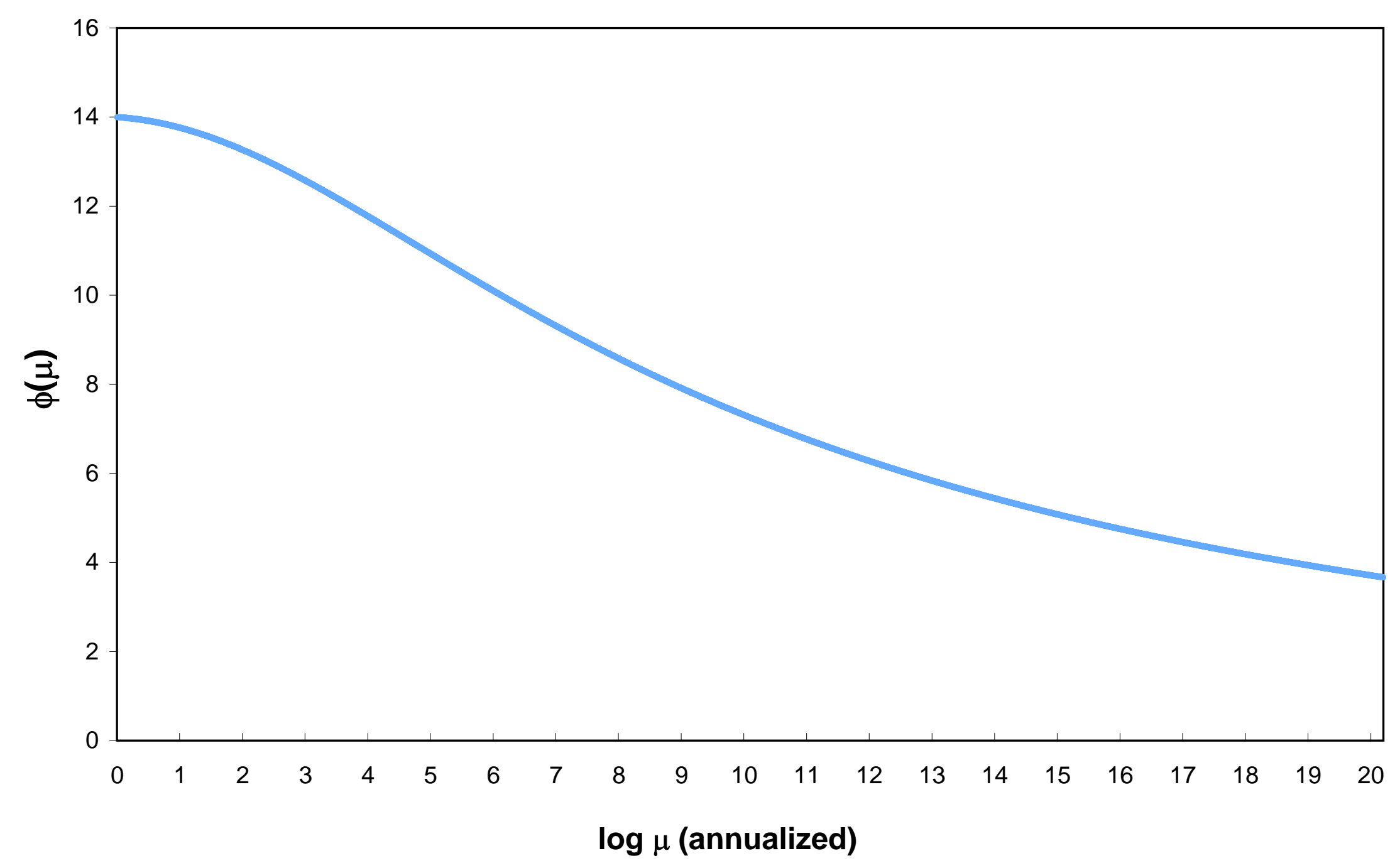


Figure 2C How the Fraction of Active Agents Is Related to the Log of Money Growth

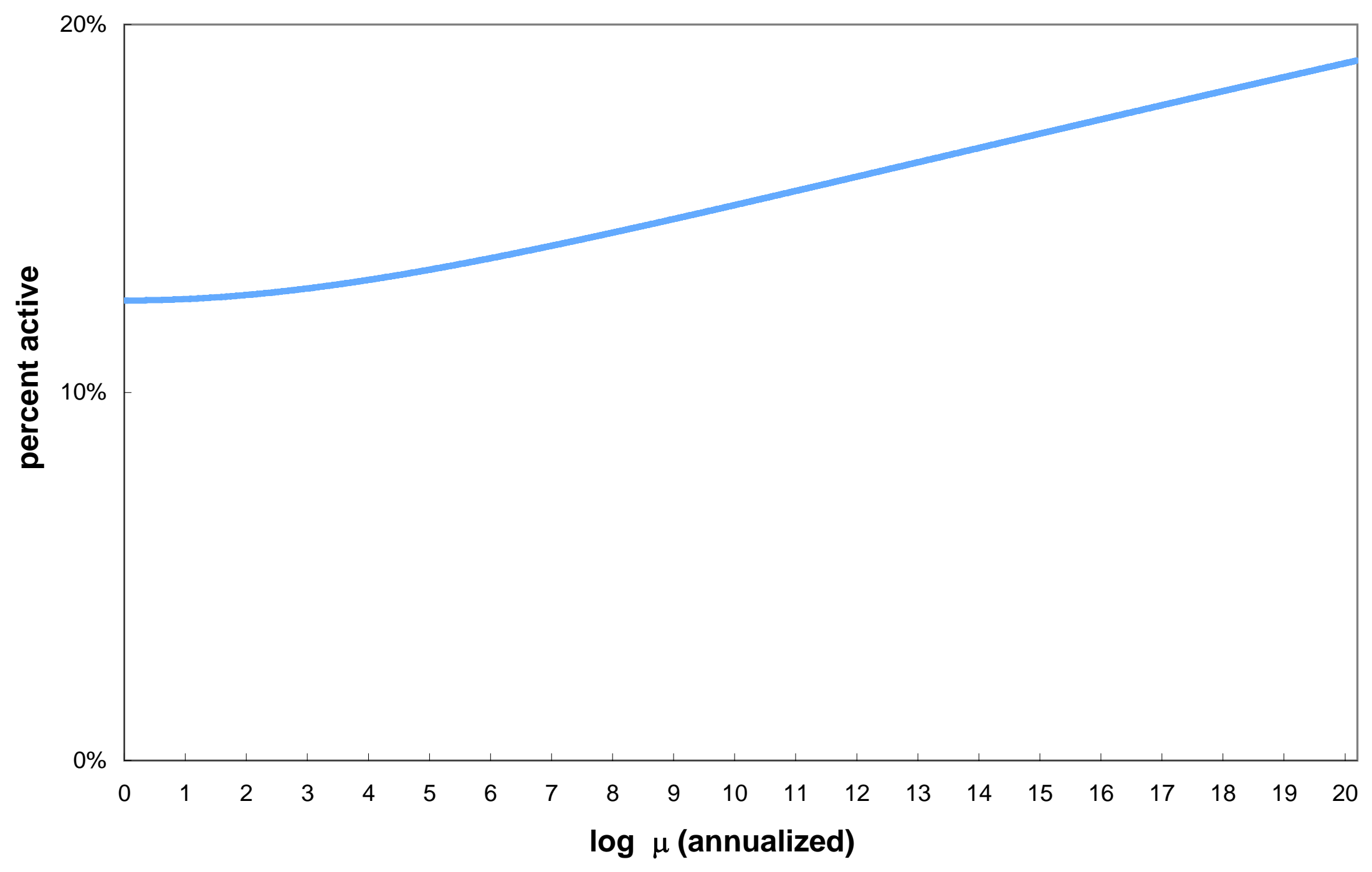


Figure 3 Realizations of Money Growth from

Our Baseline Process and an AR(1) Process

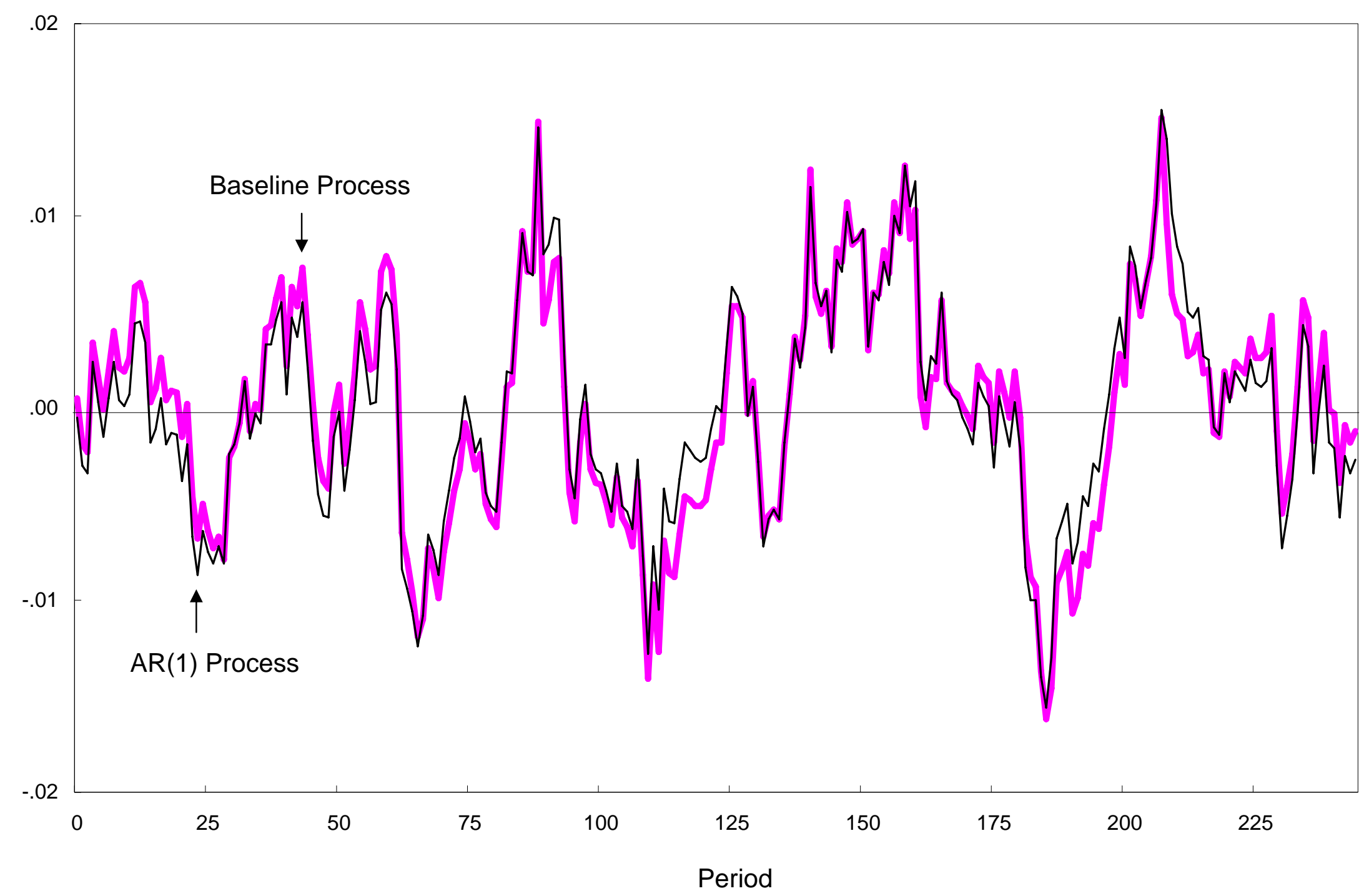




\section{Figure 4 The Cross Section Average Interest Rate Differentials and Exchange Rate Changes}

Figure 4A In the Data

Average One-Month Interest Rate Differential (U.S. Less Other Country) vs. Average One-Month Change in Exchange Rate (with U.S. Dollar) January 1976-March 1998, for 14 Countries*

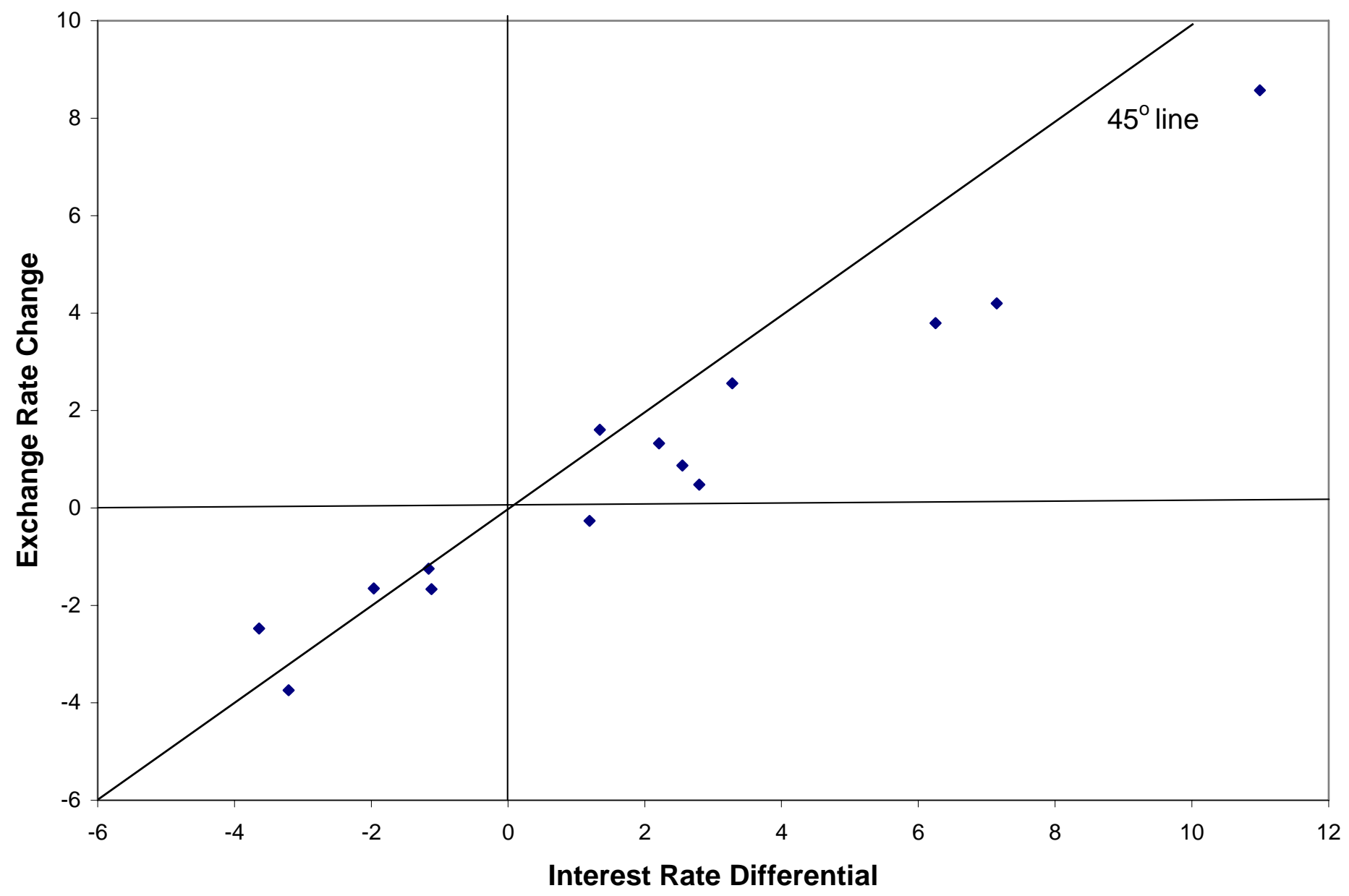

*The countries are Austria, Belgium, Canada, Denmark, England, France, Germany, Italy, Japan, the Netherlands, Portugal, Spain, Sweden, and Switzerland.

Sources: Data studied in Ravi Bansal and Magnus Dahlquist 2000 


\section{Figure 4B In the Model}

Average One-Month Interest Rate Differential (Home Less Foreign Country) vs.

Average One-Month Change in Exchange Rate (with Home Currency)

Over 245 Months**

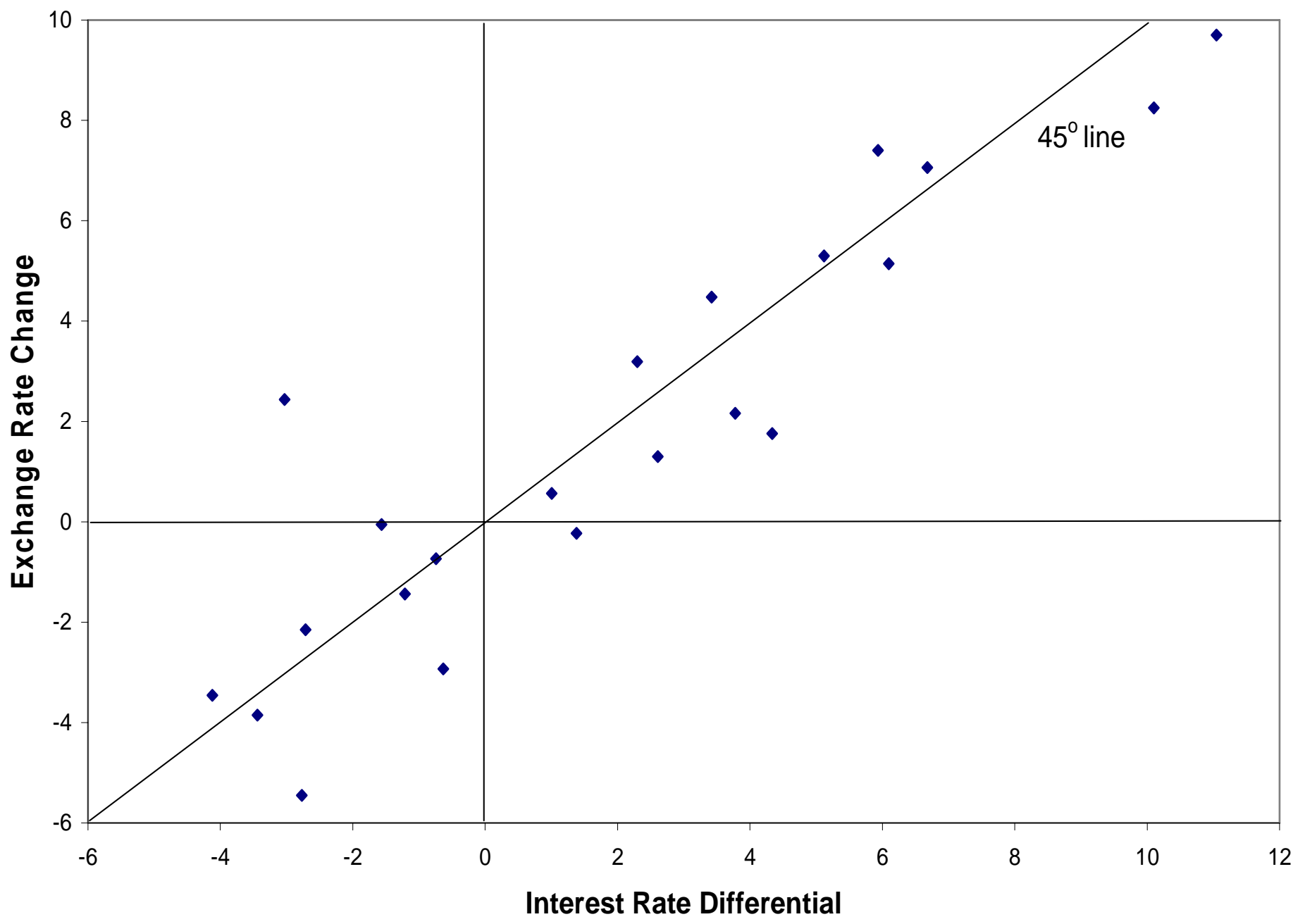

${ }^{*}$ For the home country, we used the baseline process for money with the permanent component of money growth $\bar{\mu}$ equal to $5 \%$ at an annual basis. We then constructed 29 foreign countries with the same process for money except that $\bar{\mu}$ varies from $1 \%$ to $12 \%$ in .5\% increments. We then computed the average one-month interest rate differential and average one-month depreciation rate over 100,000 simulations of length 245. 


\section{Table 1}

Interest and Exchange Rates in the Data and the Model

Monthly

\begin{tabular}{lccccc}
\hline & \multicolumn{2}{c}{ Standard Deviations } & & \multicolumn{2}{c}{ Autocorrelations } \\
\cline { 2 - 3 } \cline { 5 - 6 } Source of Statistic & $\begin{array}{c}\text { Interest Rate } \\
\text { Differentials }\end{array}$ & $\begin{array}{c}\text { Exchange } \\
\text { Rate Changes }\end{array}$ & & $\begin{array}{c}\text { Interest Rate } \\
\text { Differentials }\end{array}$ & $\begin{array}{c}\text { Exchange } \\
\text { Rate Changes }\end{array}$ \\
\hline U.S. vs. Euro Data & .3 & 3.0 & & .83 & .04 \\
Model Predictions & & & & & .92 \\
$\quad$ With $b=0$ & .1 & 4.8 & & .92 & 0 \\
With $b=-1$ & .1 & 4.8 & & .89 & 0 \\
With Exogenous Segmentation & .003 & 3.1 & & & 0 \\
\hline
\end{tabular}

Note: The data values are based on Backus, Foresi, and Telmer's (2001) monthly values on U.S. and euro currencies from July 1974 through November 1994. In the model denoted $b=0$, the process for money is chosen so that the slope coefficient in the Fama regression equals 0; in the model denoted $b=-1$, that coefficient equals -1 . In the model denoted Exogenous Segmentation, the fraction of active households is fixed at $F(0)$. The standard deviations have been multiplied by 100 to express them in percentage points. To annualize them, multiply each by 12 . 


\section{Table 1}

Interest and Exchange Rates in the Data and the Model

Monthly

\begin{tabular}{lccccc}
\hline & \multicolumn{2}{c}{ Standard Deviations } & & \multicolumn{2}{c}{ Autocorrelations } \\
\cline { 2 - 3 } \cline { 5 - 6 } Source of Statistic & $\begin{array}{c}\text { Interest Rate } \\
\text { Differentials }\end{array}$ & $\begin{array}{c}\text { Exchange } \\
\text { Rate Changes }\end{array}$ & & $\begin{array}{c}\text { Interest Rate } \\
\text { Differentials }\end{array}$ & $\begin{array}{c}\text { Exchange } \\
\text { Rate Changes }\end{array}$ \\
\hline U.S. vs. Euro Data & .3 & 3.0 & & .83 & .04 \\
Model Predictions & & & & & .92 \\
$\quad$ With $b=0$ & .1 & 4.8 & & .92 & 0 \\
With $b=-1$ & .1 & 4.8 & & .89 & 0 \\
With Exogenous Segmentation & .003 & 3.1 & & & 0 \\
\hline
\end{tabular}

Note: The data values are based on Backus, Foresi, and Telmer's (2001) monthly values on U.S. and euro currencies from July 1974 through November 1994. In the model denoted $b=0$, the process for money is chosen so that the slope coefficient in the Fama regression equals 0; in the model denoted $b=-1$, that coefficient equals -1 . In the model denoted Exogenous Segmentation, the fraction of active households is fixed at $F(0)$. The standard deviations have been multiplied by 100 to express them in percentage points. To annualize them, multiply each by 12 . 